\title{
Laser Additive Manufacturing on Metal Matrix Composites: A Review
}

\author{
Neng Li, Wei Liu, Yan Wang, Zijun Zhao, Taiqi Yan, Guohui Zhang and Huaping Xiong ${ }^{*}$
}

\begin{abstract}
Important progresses in the study of laser additive manufacturing on metal matrix composites (MMCs) have been made. Recent efforts and advances in additive manufacturing on 5 types of MMCs are presented and reviewed. The main focus is on the material design, the combination of reinforcement and the metal matrix, the synthesis principle during the manufacturing process, and the resulted microstructures as well as properties. Thereafter, the trend of development in future is forecasted, including: Formation mechanism and reinforcement principle of strengthening phase; Material and process design to actively achieve expected performance; Innovative structure design based on the special properties of laser AM MMCs; Simulation, monitoring and optimization in the process of laser AM MMCs.
\end{abstract}

Keywords: Laser additive manufacturing, Metal matrix composites, Microstructure, Property

\section{Introduction}

Metal matrix composites (MMCs) are fabricated by continuously dispersing a reinforcing material into a monolithic metallic material matrix [1]. The MMCs could possess both the ductility and toughness of metals as well as high strength and stiffness of reinforcement particles [2].

Recently, the interest of MMCs was particularly increasing due to their superior properties of high modulus and strength, good wear resistance, outstanding chemical inertness, and excellent properties at elevated temperatures $[3,4]$. The MMCs become favorable materials applied under severe working conditions (e.g., high-load condition, high-wear/friction condition, hightemperature condition) in the advanced aerospace and automobile industries [5]. Matrix based on $\mathrm{Al}, \mathrm{Co}, \mathrm{Cu}, \mathrm{Fe}$, $\mathrm{Mg}, \mathrm{Ni}$ and $\mathrm{Ti}$ are all commercially produced and used. For structural applications, the matrix is usually a lighter metal, such as aluminum and titanium provided a compliant support for the reinforcement. In the meantime,

*Correspondence: xionghp69@163.com

3D Printing Research \& Engineering Technology Center, Beijing Institute of Aeronautical Materials, Beijing 100095, China for high-temperature applications nickel and cobalt alloy matrix are commonly used [6, 7].

Most common reinforcements used in commercial applications are $\mathrm{Al}_{2} \mathrm{O}_{3}, \mathrm{~B}_{4} \mathrm{C}, \mathrm{BeO}, \mathrm{NbC}, \mathrm{SiC}, \mathrm{TaC}, \mathrm{TiB}$, $\mathrm{TiC}$ and $\mathrm{WC}$. The largest volume of the commercially used reinforcement is $\mathrm{SiC}$ by a significant margin, which is followed by $\mathrm{Al}_{2} \mathrm{O}_{3}$ and $\mathrm{TiC}$ [8].

Recently, the additive manufacturing (AM) technology has attracted a great deal of attentions and is under intensive investigations for fabricating MMCs $[9,10]$.

AM is described by the American Society for Testing and Materials (ASTM) as "a process of joining materials to make objects from 3D model data, usually layer upon layer, as opposed to subtractive manufacturing technologies" [11]. Compared with conventional manufacturing methods, AM has extended capability of fabricating complex shaped parts and presented benefits of high design flexibility, high customization, no need of assembly or molds, etc. [12, 13].

In the laser AM process to fabricate MMCs, the raw materials are either premixed using ball milling machine (option 1) or mixed from powder feeders (option 2). For option 2, the weight ratio between different materials can be controlled via regulating the feeding rate of each powder feeder [9]. 
In this paper important recent efforts and advances in the study of laser AM MMCs are reviewed and the main focus is on the material design, the combination of reinforcements and matrix, the synthesis principle during the manufacturing process and the resulted microstructures and properties. 5 types of laser AM MMCs are discussed, and lots of significant research results have been achieved. Based on these research results, some important developing focuses are proposed for the future work.

\section{Progress in Additive Manufacturing on Metal Matrix Composites}

\subsection{Aluminum Matrix Composites}

Aluminum matrix composites (AMCs) refer to the composites with an addition of reinforcements to aluminum alloys. The reinforcements could improve different properties of the composites, such as strength, modulus, heat resistance, wear resistance, dimensional stability and thermal conductivity $[14,15]$. These improvements showed broad application prospects in the fields of aerospace, automotive, power electronics, and so on [16-18].

Based on the technical features, the laser AM process are usually used for fabricating particles-reinforced AMCs. These AMCs have the advantages of excellent mechanical properties, simple fabricating process and low manufacturing cost, which lead to a more extensive research and application [19-21]. The type, size, morphology, distribution state and volume fraction of the reinforcements have a great impact on the manufacturing cost and mechanical properties of the composites [22].

According to the different ways of introducing the reinforcement, the processes of laser AM AMCs are generally divided into two categories: external additive method and in-situ synthesis method.

The external additive method means directly adding the reinforcements to the matrix during laser AM process. In order to make the reinforcements be uniformly distributed in the matrix, the raw materials should be perfectly mixed together. Common reinforcing particles mainly include $\mathrm{SiC}, \mathrm{TiC}, \mathrm{AlN}, \mathrm{BN}, \mathrm{Si}_{3} \mathrm{~N}_{4}, \mathrm{Al}_{2} \mathrm{O}_{3}, \mathrm{ZrO}_{2}$, $\mathrm{TiO}_{2}$, etc.

Zhou et al. [19] investigated the effects of different TiC contents on the microstructural evolution and mechanical property of hypereutectic Al-15Si alloy manufactured by selective laser melting (SLM). The Al-15Si powders with spherical shape of about $21.2 \mu \mathrm{m}$ in diameter and the $99.0 \%$ purity $\mathrm{TiC}$ powders with polygonal shape of about $6.7 \mu \mathrm{m}$ were used. The results showed that with the increasement of the $\mathrm{TiC}$ content from 0 to $10 \mathrm{wt} . \%$, the $\mathrm{TiC}$ solubility decreased rapidly due to the decreased undercooling degree. Simultaneously, the network eutectic Si microstructure becoming coarse and some small Si particles precipitated out and distributed on the surface of AMCs, as shown in Figure 1. As the content of TiC increased, the micro-hardness firstly decreased (146 $\mathrm{Hv})$ and then increased $(177 \mathrm{Hv})$. Conversely, the tensile strength firstly rose to $578 \mathrm{MPa}$ and then decreased sharply to $313 \mathrm{MPa}$. It was inferred that the $\mathrm{TiC}$ addition changed the thermodynamic and thermokinetic characteristics of the melting pool, such as the undercooling degree and transfer capacity of atoms.

Kang et al. [23] investigated the microstructure and wear behavior of Al91Fe4Cr5 quasicrystal (QC) reinforced $\alpha$-Al matrix composite prepared by SLM. The results showed that the QC particle size changed from hundreds of nanometers to several micrometers with the increasement of laser power. Meanwhile, the inner dense structure of the QC particles becomes porous. It was attributed to the transformation of QC to crystal with the higher energy density. Additionally, a mixed microstructure was observed including partially melted QC, micro-QC and nano-QC at relatively low laser power. The test results indicated that the mixed microstructure presented the highest wear resistance $\left(2.64 \times 10^{-4}\right.$ $\left.\mathrm{mm}^{3} / \mathrm{N} \cdot \mathrm{m}\right)$. That was because the partially melted QC particle exhibited higher hardness than that of the other phases in the composites. However, cracks were easily found on the composites due to the low ductility.

Li et al. [24] studied the effects of TiBCN contents on the microstructure and properties of the coatings on 7075 aluminum alloy by laser cladding. The coating was composed of Ti and TiBCN. Ti powder of 100-150 $\mu \mathrm{m}$ and TiBCN powder of $100-150 \mu \mathrm{m}$ were mixed with different weight ratio of TiBCN (0 wt.\%, 5 wt.\%, 10wt.\%, $15 \mathrm{wt} . \%)$ and then the mixture was laser cladded. The results showed that for the clad layer with the TiBCN content of $15 \mathrm{wt} . \%$, the microstructure of coating zone mainly composed of equiaxed grains and white lath-like crystals uniformly distributed in the equiaxed grains, as shown in Figure 2(a). In the transition zone, elongated dendrite crystals and white small particles were obtained, as shown in Figure 2(b). As TiBCN content in the coating zone increases, the average hardness values increased gradually. Furthermore, the clad layer with the TiBCN content of 15 wt.\% exhibited a maximum corrosion resistance and a minimum average friction coefficient.

To study the influence of reinforcement on the laser energy absorption behaviors, laser absorptivity percentages along the laser beam path were calculated on 3 typical systems, such as pure $\mathrm{AlSi10Mg}, \mathrm{SiC} / \mathrm{AlSi10Mg}$ and $\mathrm{TiB}_{2} / \mathrm{AlSi} 10 \mathrm{Mg}$ [25], as Figure 3 showed. It was found that the reinforcements enhanced the interactions between laser beam and powder particles, which were illustrated by an increasing laser ray track spots on the particle surfaces. With the laser beam moving, the absorptivity of pure AlSi10Mg powder-bed ranged from 

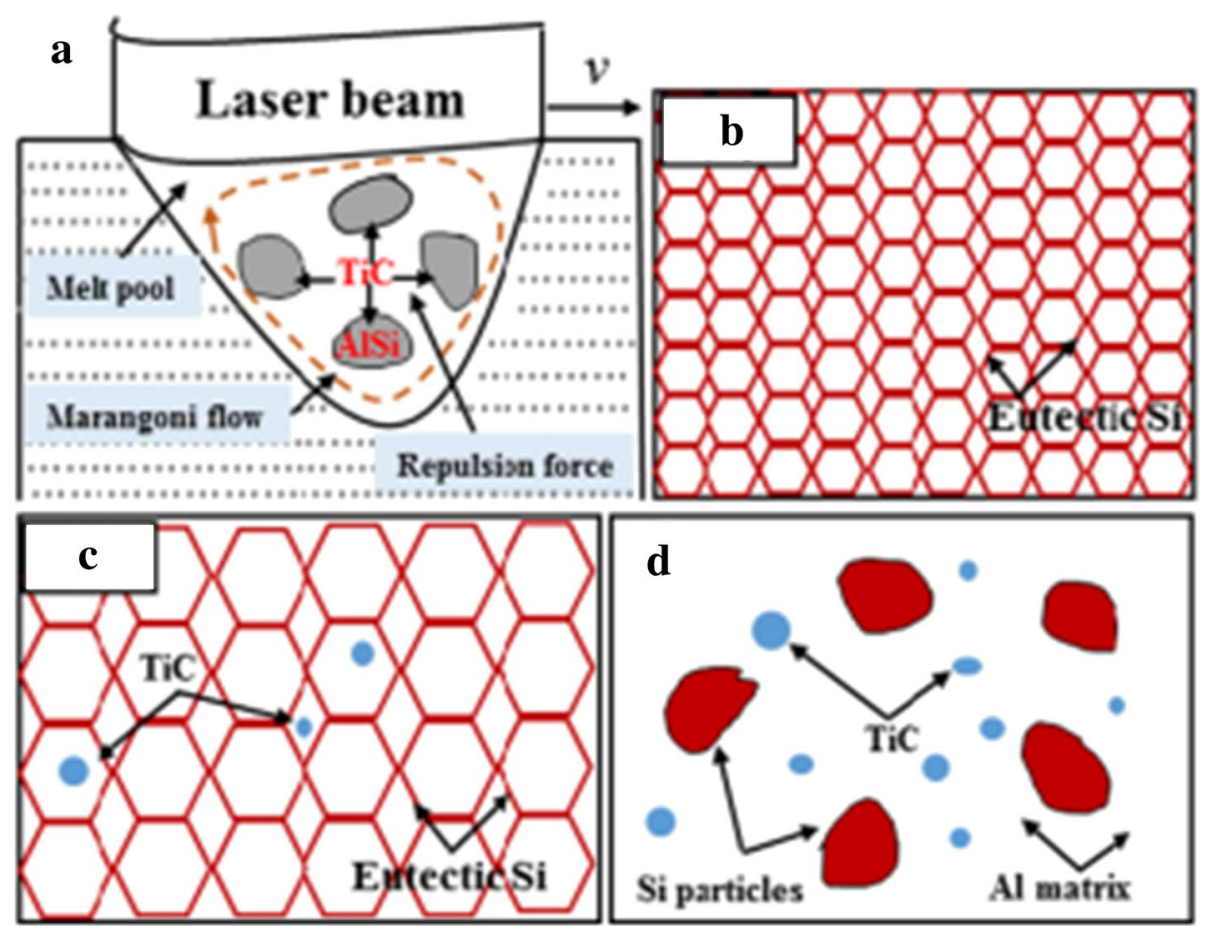

Figure 1 a The schematic describing the formation mechanism of Al-15Si/TiC structure, b Al-15Si, c Al-15Si/1.0-2.5 wt\% TiC, d Al-15Si/10 wt\% TiC [19]
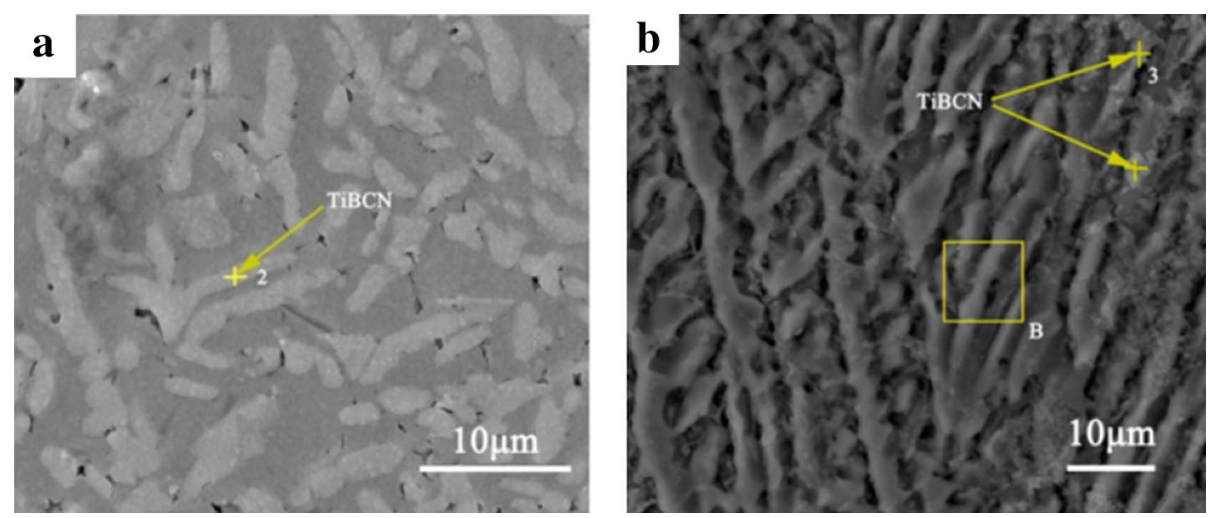

Figure 2 a SEM cross-section microstructure morphology of coating zone, b SEM cross-section microstructure morphology of transition zone [24]

0.19 to 0.32 . A respective absorptivity fluctuated from 0.37 to 0.59 and 0.34 to 0.49 for the randomly packed $\mathrm{SiC} / \mathrm{AlSi} 10 \mathrm{Mg}$ and $\mathrm{TiB}_{2} / \mathrm{AlSi} 10 \mathrm{Mg}$, both of which were significantly enhanced compared with that of AlSi10Mg powder. Moreover, the results indicated that $\mathrm{SiC}$ reinforcement was more effective than $\mathrm{TiB}_{2}$ in the enhancement of laser absorption behaviors.

However, if the reinforcement particles are surface treated or surface modified, complex process will be involved. Many challenges still existed due to the poor compatibility with the reinforcement-matrix interface, contamination of the particle surfaces, and so on. As a result, it was difficult for the AMCs prepared by direct additive method to exert the full advantage of the reinforcements, and the property improvement was greatly restricted [26].

On the other hand, concerning in-situ method, it utilized the in-situ chemical reactions between metal matrix and raw reinforcement materials to generate reinforced phase particles, which can effectively solve the problems 


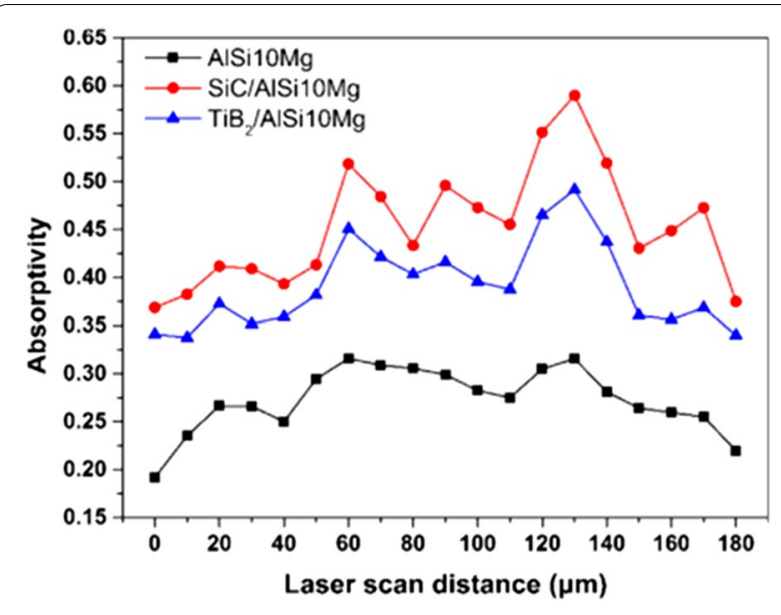

Figure 3 Laser absorptivity along the beam path of pure AISi10Mg, $\mathrm{SiC} / \mathrm{AlSi} 10 \mathrm{Mg}$ and $\mathrm{TiB}_{2} / \mathrm{AlSi} 10 \mathrm{Mg}[25]$

of poor compatibility of AMCs and achieve the comprehensive performance of the composites [27].

$\mathrm{Al} / \mathrm{SiC}_{\mathrm{p}}$ coatings were laser deposited on $\mathrm{AA} 6082$ aluminum alloy and the AM process was analyzed by
Riquelme et al. [28]. The addition alloying elements $(\mathrm{Si}$ or $\mathrm{Ti}$ ) and $\mathrm{SiC}$ had effects on the formation reaction of $\mathrm{Al}_{4} \mathrm{C}_{3}$. Under the action of laser, the $\mathrm{SiC}$ particles were completely dissolved and reacted with $\mathrm{Ti}$ and $\mathrm{Al}$ in the melting pool. Therefore, it was not strange to observe a ring shape of $\mathrm{TiC}$ phase surrounded of a small $\mathrm{SiC}$ particle and $\mathrm{Al}_{4} \mathrm{C}_{3}$ particles. Besides, molten Ti reacted with $\mathrm{Si}$ and formed $\mathrm{TiSi}_{2}$. All these in-situ reaction products were ultra-fine and distributed uniformly.

Lijay et al. [29] fabricated AA6061/TiC AMCs using in-situ reaction of inorganic salt $\mathrm{K}_{2} \mathrm{TiF}_{6}$ and ceramic particle $\mathrm{SiC}$ with molten aluminum. The results showed that a large number of in-situ formed $\mathrm{TiC}$ particles were uniformly distributed in inter granular regions and effectively refined the grains of aluminum matrix (Figure 4). The $\mathrm{TiC}$ particles exhibit various shapes like cubic, spherical and hexagonal, as shown in Figure 5. All the $\mathrm{TiC}$ particles presented characteristics of homogeneous distribution, clear interface and good bonding. Therefore, the formation of TiC particles improved the micro-hardness and mechanical properties of the AMCs.

However, in current stage, the in-situ method is difficult to achieve precise control on the size and content

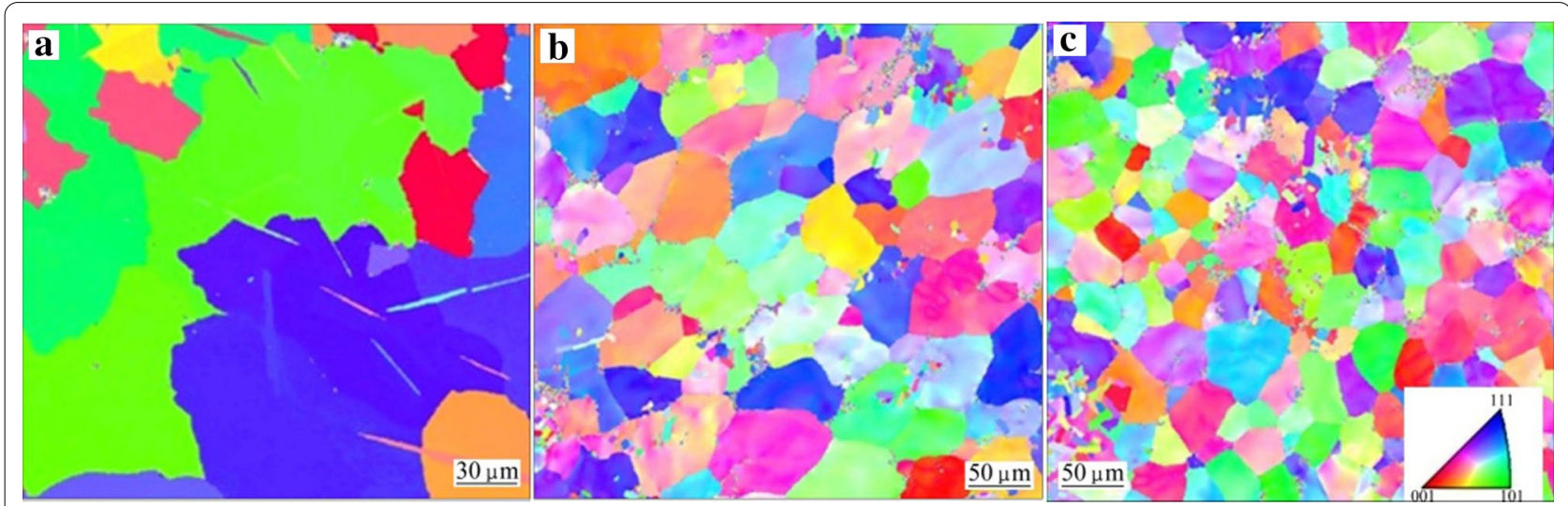

Figure 4 EBSD maps of AA6061/TiC in-situ composites containing TiC: a 0, b 2.5\%, c 5\% [29]
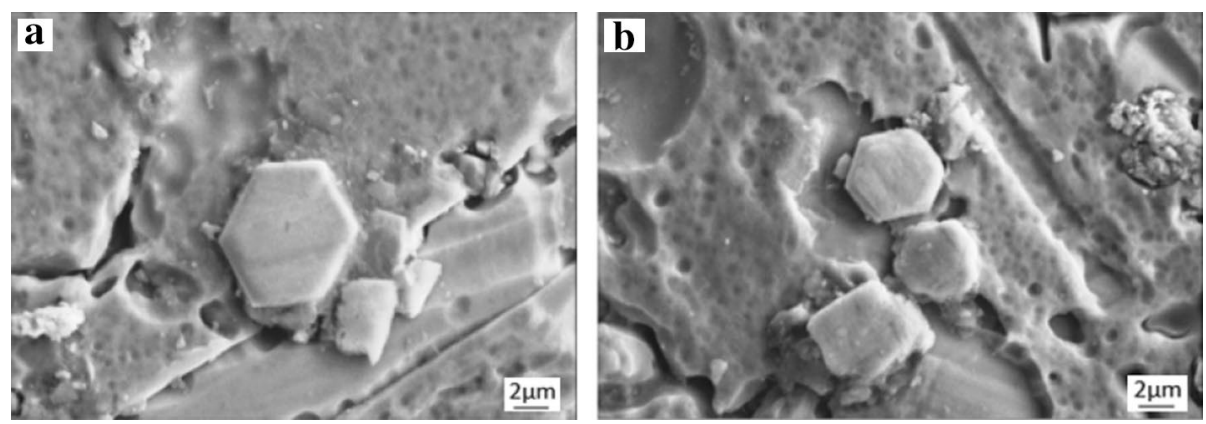

Figure 5 SEM images of AA6061/TiC in site composites at higher magnification containing TiC: a 2.5\%, b 5\% [29] 
of the reinforcements. Only a few material systems were studied and further investigation were needed in the future [30-32].

Compared with the AMCs formed by direct adding reinforcements, the AMCs prepared by in-situ reaction method overcomes the defects of particle surface pollution and poor bonding between reinforcement and matrix. Therefore, a better comprehensive performance could be easier obtained by the in-situ laser AM method.

\subsection{Titanium Matrix Composites}

Titanium matrix composites (TMCs) exhibited excellent properties of high hardness, high strength, high temperature resistance, making them an ideal substitute for metals and alloys in some cases [33-36].

TMCs also become an effective way to improve the properties of Titanium alloys [37-39]. TMCs can be divided into continuous reinforced TMCs and discontinuous reinforced TMCs. Concerning the technical features of laser AM, the continuous reinforcements, such as carbon fiber $\left(C_{f}\right)$ and silicon carbide fiber $\left(\mathrm{SiC}_{\mathrm{f}}\right)$ were difficult to survive under the action of laser. Therefore, most of the research focused on discontinuous reinforced TMCs, especially particle reinforced TMCs [40-43].

Carbide, silicide, oxide, boride and other intermetallic compounds with high modulus and high strength were often selected in particle reinforced TMCs. The commonly used reinforcements included $\mathrm{TiC}, \mathrm{TiB}$ and $\mathrm{SiC}$ and rare earth oxides, such as $\mathrm{Y}_{2} \mathrm{O}_{3}$ [44-47]. For example, $\mathrm{TiC}$ was thermodynamically compatible with titanium alloy. Its density, Poisson's ratio and thermal expansion coefficient were similar to titanium alloy and the modulus and strength were far higher than those of titanium. All the advantages above made it an ideal reinforcement for TMCs. Normally, there was no obvious reaction between $\mathrm{TiC}$ and the titanium matrix. However, when $\mathrm{SiC}$ particles were added into titanium alloy, chemical reactions were easily generated with titanium matrix at the contact place due to an unstable interface junction [48-50].

Like the laser AMed AMCs, the laser AMed TMCs also could be mainly divided into two methods. One method was directly adding particulate reinforcements to the titanium matrix to prepare TMCs, which needs to deal with lots of limitations, such as the wetting problem between reinforcement phase and matrix, the interfacial reaction. On the other hand, in recent years, the preparation of TMCs by in-situ reaction has become a research hotspot in the field of TMCs. In-situ synthesis was a method by adding certain materials into the metal matrix to stimulate the chemical reactions between each other, generating reinforcements during the in-situ synthesis process.

Compared with the traditional external adding method, the in-situ synthesis method has the following advantages: firstly, the in-situ reinforced products were more stable in the matrix, which would be not easy to decompose at high temperatures. Secondly, this in-situ synthesis was capable of achieving a clean interface, so as to produce a good metallurgical bonding between the matrix and the reinforcement phase. Finally, the size of the in-situ generated reinforcement particles was fine, and the distribution in the matrix was more uniform, which can better improve the mechanical properties [51, 52].

Hooyar et al. $[53,54]$ prepared $\mathrm{Ti}$ and in-situ $\mathrm{Ti} / \mathrm{TiB}$ composites by SLM technology using commercial pure Ti and titanium diboride $\left(\mathrm{TiB}_{2}\right)$ powders as raw materials. By optimizing the processing parameters of SLM, almost completely dense samples (with density greater than 99.5\%) was obtained. It was found that $\mathrm{Ti}$ was mainly composed of martensite $\alpha$ - Ti phase because of the high cooling rate in SLM process. The AMed Ti/TiB composite was mainly composed of $\alpha$-Ti matrix phase, and the needle-like $\mathrm{TiB}$ phases were randomly distributed in the matrix phase, as shown in Figure 6, indicating that $\mathrm{TiB}_{2}$ reduced the transformation temperature of martensite, resulting in the matrix structure of $\alpha$-Ti. The results also showed that the maximum compressive stress of Ti forming part was $1136 \mathrm{MPa}$, whereas that of $\mathrm{Ti} / \mathrm{TiB}$ composite could be increased to $1421 \mathrm{MPa}$.

Cai et al. [55] also prepared TiB reinforced Ti-6Al-4V composites by adding $\mathrm{TiB}_{2}$ particles into titanium alloy through SLM. The microhardness of the composite reached $6.0 \mathrm{GPa}$, which was much higher than that of the traditional sintering products. The TiB reinforced TMCs also significantly improved the wear resistance. Feng [56] prepared $\left(\mathrm{Ti}_{3} \mathrm{Al}+\mathrm{TiB}\right) / \mathrm{Ti}$ composites on Ti6Al4V matrix by laser cladding, which significantly improved the wear resistance and high temperature resistance of the matrix. Xia et al. [57] prepared in-situ $\mathrm{TiB}$ and $\mathrm{TiC}$ reinforced TMCs using $\mathrm{B}_{4} \mathrm{C} / \mathrm{Ti}$ composite powders by SLM and

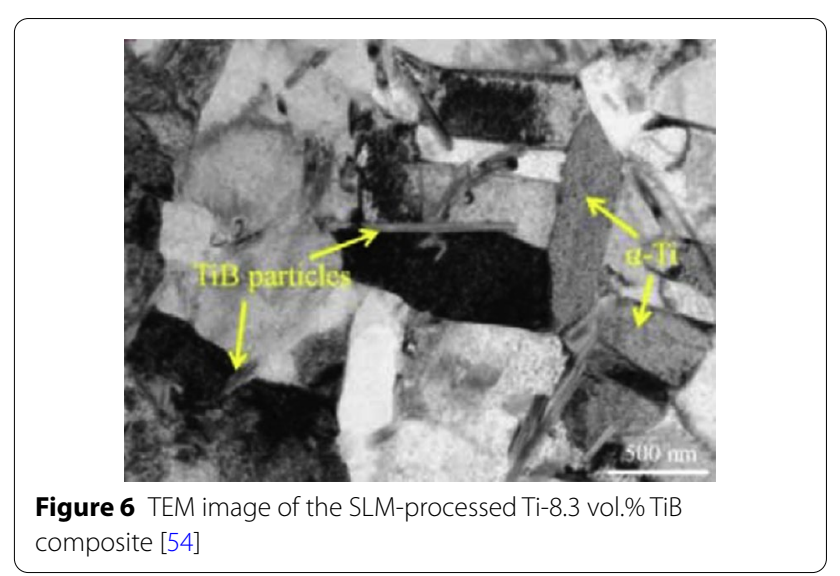


obtained TMCs with low wear rate by adjusting process parameters.

Li et al. [58] manufactured ceramic reinforced TMCs by laser AM using ball milling treated mixtures of $\mathrm{Ti}$ and $\mathrm{SiC}$ powder particles. Two laser cladded layers of $90 \% \mathrm{Ti}+10 \% \mathrm{SiC}$ and $80 \% \mathrm{Ti}+20 \% \mathrm{SiC}$ were deposited onto the Ti6Al4V substrate. Chemical reactions took place between the $\mathrm{Ti}$ and $\mathrm{SiC}$ particles in the composite layers, and the reaction products consisted of $\mathrm{TiC}$ and $\mathrm{Ti}_{5} \mathrm{Si}_{3}$, as shown in Figure 7. The formed $\mathrm{Ti}_{5} \mathrm{Si}_{3}$ particles present an average size of about $200 \mathrm{~nm}$ and $\mathrm{TiC}$ ones about $1 \mu \mathrm{m}$. The $80 \% \mathrm{Ti}+20 \% \mathrm{SiC}$ cladded layer increased the hardness of the Ti6Al4V matrix from $339.1 \mathrm{HV}$ to 932.2 $\mathrm{HV}$, and this was mainly attributed to the high hardness of the $\mathrm{TiC}$ and $\mathrm{Ti}_{5} \mathrm{Si}_{3}$. As a consequence, the wear resistance was improved remarkably, as shown in Figure 8.

In the application of $\mathrm{Ti}-\mathrm{Si}-\mathrm{C}$ composite powder, the $\left(\mathrm{TiC}+\mathrm{Ti}_{3} \mathrm{SiC}_{2}\right)$ reinforced TMCs were fabricated successfully [59]. In-situ chemical reactions took place
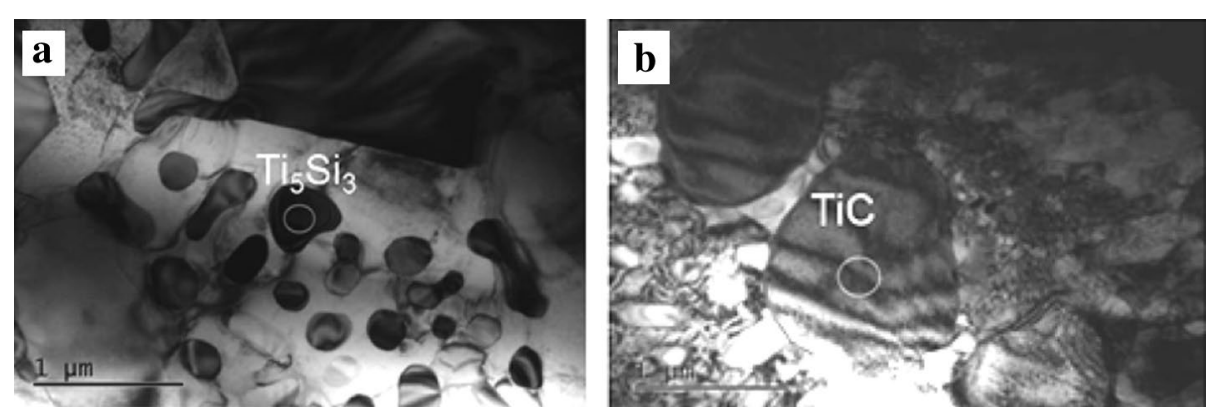

Figure 7 TEM bright field image: a $\mathrm{Ti}_{5} \mathrm{Si}_{3}$ particles and $\mathbf{b} \mathrm{TiC}$ particles [58]
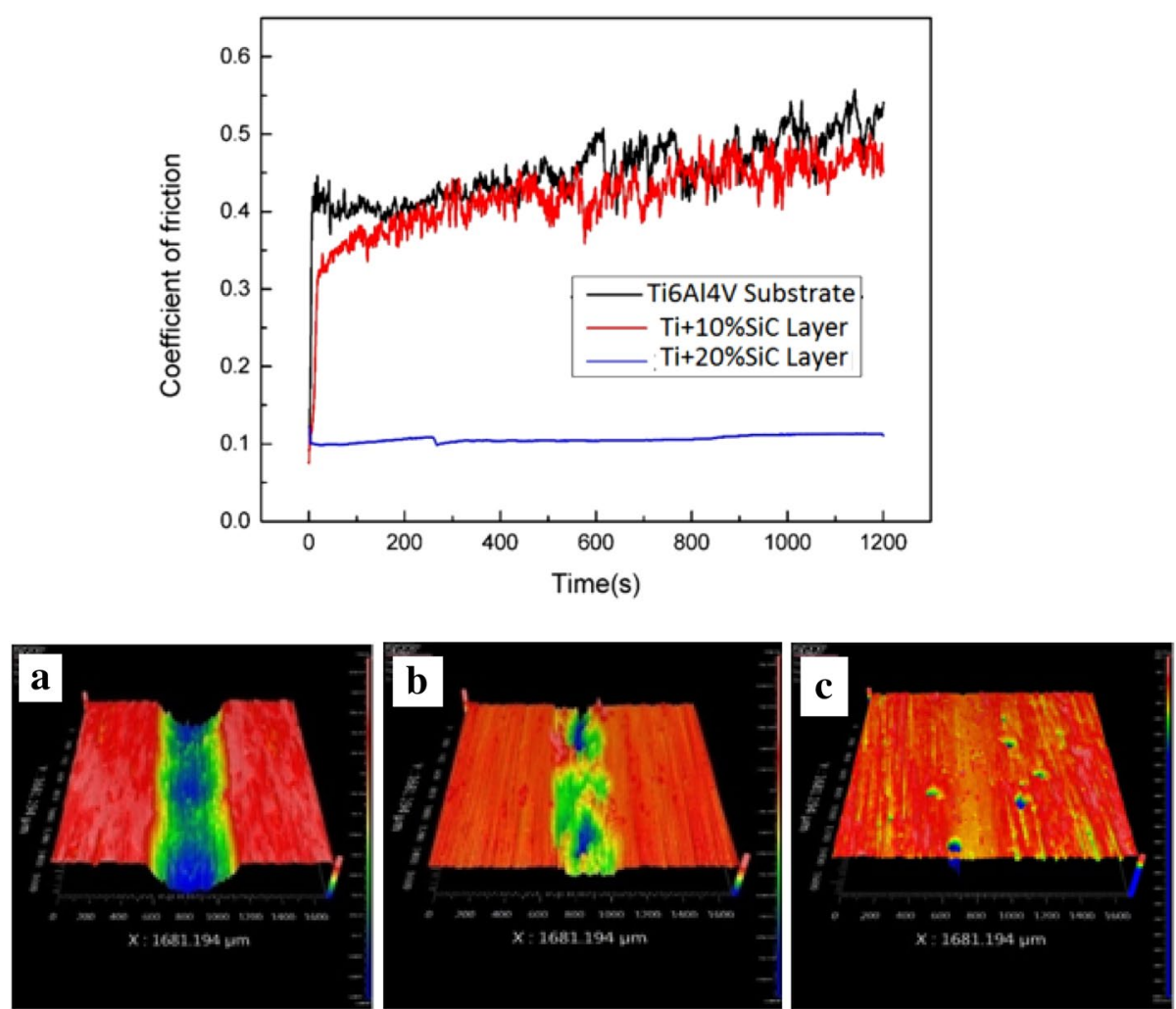

Figure 8 Friction coefficient as a function of time for the two cladded coatings and the Ti6Al4V substrate and Worn surface morphology [58]: a Bare alloy, b 90\% Ti+10\% SiC layer, c 80\% Ti + 20\% SiC graded layer 
between elements $\mathrm{Ti}, \mathrm{Si}$ and $\mathrm{C}$ in the deposited layers, and the reaction products included $\mathrm{TiC}$ and $\mathrm{Ti}_{3} \mathrm{SiC}_{2}$ ceramics as well as $\mathrm{Ti}_{5} \mathrm{Si}_{3}$ compound. With the modification of the specific ratio of Ti element, Si element and $\mathrm{C}$ element, the microstructure of TMCs would present different characteristics, as shown in Figure 9. When the content of $\mathrm{Si}$ and $\mathrm{C}$ elements was low, the reinforcements were mainly $\mathrm{TiC}$ particles. As the $\mathrm{Si}$ and $\mathrm{C}$ elements increased, the ductile ceramic $\mathrm{Ti}_{3} \mathrm{SiC}_{2}$ phase appeared and prevented the occurrence of cracks [60-63].

\subsection{Iron Matrix Composites}

Iron matrix composites (IMCs), reinforced by ceramic particles, have received a consistent attention in recent years. However, the IMCs processed by conventional methods usually have poor density, weak strength and high cracking susceptibility caused by poor wettability and large residual stress owing to the coefficient of thermal expansion mismatch between reinforcing particles and matrix, which may lead to cracks, seriously affecting the mechanical performance. In order to solve these problems, many researchers have tried to introduce laser AM methods to fabricate IMCs [64-68]. The processes of laser AM IMCs were also carried out by two methods: external additive method and in-situ method.

Gu et al. [65] investigated the microstructure and wear resistance of laser AM WC reinforced IMCs. The microhardness of IMCs enhanced to $511.6 \mathrm{HVO} 0.2$ and a low friction coefficient of 0.30 was achieved with a low wear rate of $3.1 \times 10^{-5} \mathrm{~mm}^{3} /(\mathrm{Nm})$. The residual WC particles was covered around by a gradient interface, as shown in Figure 10, which was identified as $\mathrm{MC}_{3}(\mathrm{M}=\mathrm{W}, \mathrm{Fe}, \mathrm{Cr}$, $\mathrm{Ni}$ ) formed between WC particle and matrix due to the in-situ reaction under laser processing. The generation of gradient interface was considered beneficial to improving the bonding strength between WC reinforcing particle and matrix. The thickness and morphology of tailoring gradient interface were influenced significantly by laser processing parameters.

Song et al. [66] reported the fabrication of $\mathrm{Cr}_{3} \mathrm{C}_{2} / \mathrm{Fe}$ nano composites using SLM. The porosity within the composite decreased when volumetric energy density increased from 27 to $37 \mathrm{~J} / \mathrm{mm}^{3}$, then rose to $55 \mathrm{~J} / \mathrm{mm}^{3}$. The results showed that the $\mathrm{Cr}_{3} \mathrm{C}_{2}$ particles decomposed completely during SLM process and interacted with $\mathrm{Fe}$ matrix to form $(\alpha-\mathrm{Fe}, \mathrm{Cr})$ solid solution and $\mathrm{M}(\mathrm{Fe}$, $\mathrm{Cr})_{23} \mathrm{C}_{6}$ carbides. In addition, due to the characteristic of rapid solidification, very fine grains were obtained throughout the composites. The tensile tests showed that the ultimate tensile strength could reach up to 1158 MPa. It is believed that the difference in the atom size of Fe and solute $\mathrm{Cr}$ could bring lattice distortion that would increase the resistance of the dislocation movement, thus improving the mechanical properties.

Some researchers had a further study on the WC reinforced maraging IMCs, which were in-situ manufactured by SLM from powder mixture [67]. The SLM processed samples presented high relative density (over

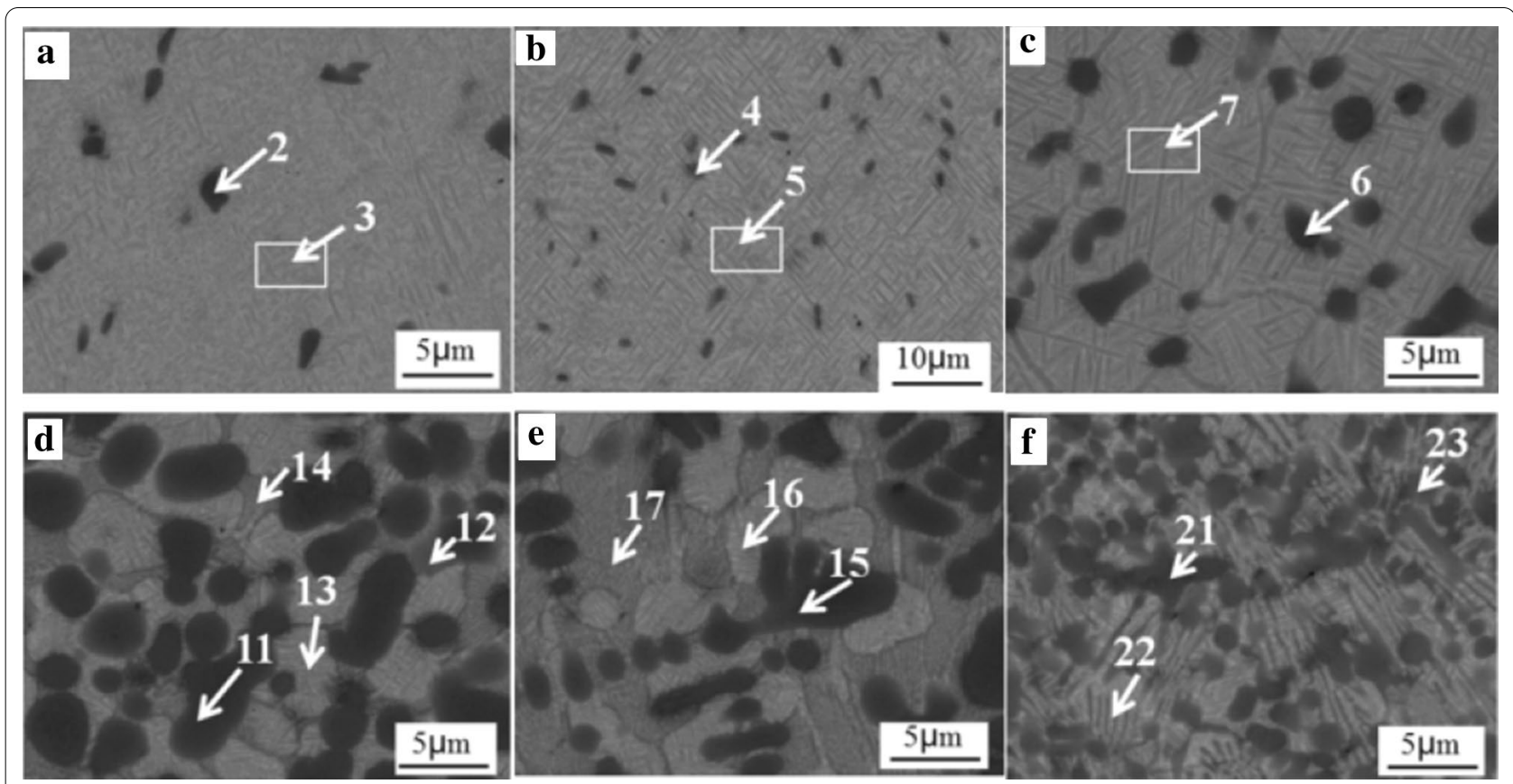

Figure 9 The BEls of typical different TMCs: a 10\%TiSiC, b 30\%TiSiC, c 50\%TiSiC, d 70\%TiSiC, e 80\%TiSiC, f 100\%TiSiC [59] 

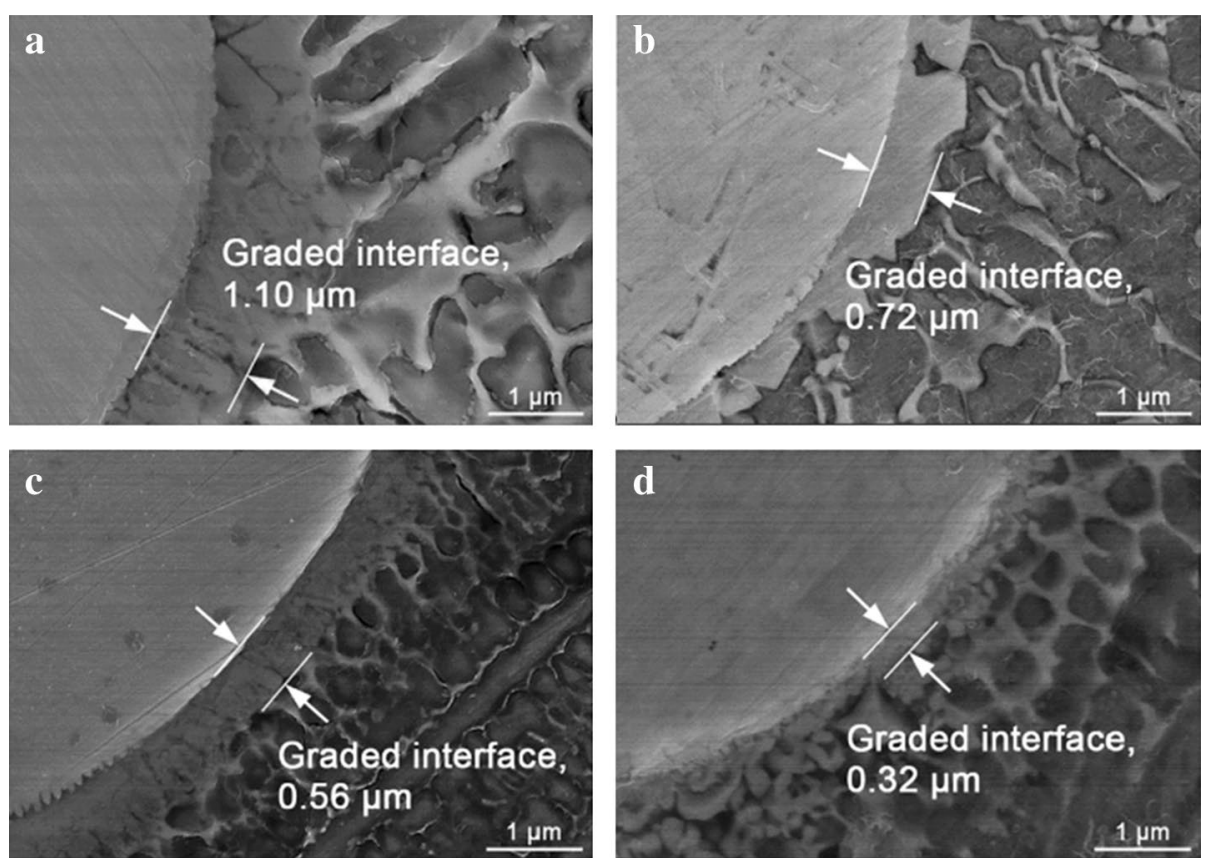

Figure 10 Morphologies of the WC particles and gradient interface of the WC reinforced Fe-based composite samples at different parameters [65]

99\%) with a homogenous distribution of WC. The asfabricated surface quality of SLM processed samples was improved significantly by the addition of WC. The interfacial analysis results indicated that elementdependent diffusion behavior took place between WC particle and maraging steel matrix during SLM process, and the SLMed composite with 5\% WC presented a maximum UTS near $1300 \mathrm{MPa}$.

Chen et al. [68] also investigated the WC reinforced high strength IMCs. The metal matrix was $1.2767 \mathrm{~L}$ tool steel. The present results show that a novel $\mathrm{Fe}_{2} \mathrm{~W}_{4} \mathrm{C}$ carbidic network precipitates in the solidified microstructure entailing segregations along the boundaries of cellular sub-grains, as shown in Figure 11. The presence of this carbidic network hampers the growth of subgrains even at elevated temperatures, and hence, stabilizes the grain size though prepared at a broad range of different energy densities. The exact distribution of the $\mathrm{Fe}_{2} \mathrm{~W}_{4} \mathrm{C}$ carbides depends on the employed laser energy densities, as for instance they are more uniformly distributed at higher energy input. The fabricated IMCs had a high microhardness up to $753 \mathrm{HV}$, the compression strength was more than $3350 \mathrm{MPa}$ and the fracture strain was $24.4 \%$. The enhanced mechanical properties are ascribed to less metallurgical defects, higher volume fraction of the martensitic phase and increasing pile-up dislocations resulting from the pinning effect by $\mathrm{Fe}_{2} \mathrm{~W}_{4} \mathrm{C}$ carbide.

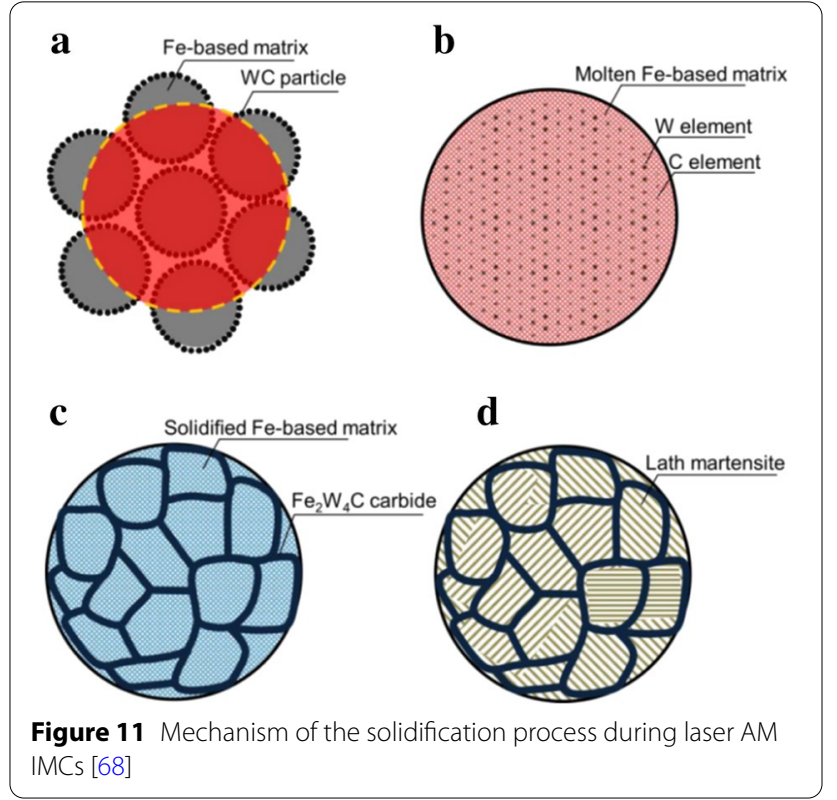

\subsection{Nickel Matrix Composites}

Ceramic reinforced Ni matrix composites (NMCs) were considered as promising materials in a wide range of applications, such as aerospace, chemical, and petrochemical industries [69-71]. Both external adding reinforcements and in-situ synthesis method were used to fabricate NMCs. 


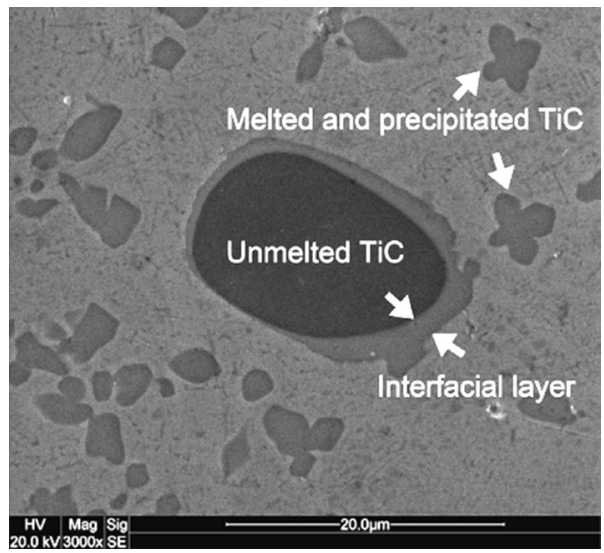

Figure 12 Microstructure of laser AM TiC/Inconel 718 NMCs [72]

Hong et al. fabricated $\mathrm{TiC}$ reinforced NMCs using laser $\mathrm{AM}$ process and proved that the presence of $\mathrm{TiC}$ reinforcement was to the benefit of refining grain size [71, 72]. A coherent interfacial layer with the thickness of $0.8-1.4 \mu \mathrm{m}$ was formed between $\mathrm{TiC}$ reinforcing particles and the matrix, which was identified as $(\mathrm{Ti}, \mathrm{M}) \mathrm{C}(\mathrm{M}$ : $\mathrm{Nb}$ and $\mathrm{Mo}$ ) layer, as shown in Figure 12. Its formation was due to the reaction of the strong carbide-forming elements $\mathrm{Nb}$ and Mo of the matrix with the dissolved $\mathrm{Ti}$ and $\mathrm{C}$ on the surface of $\mathrm{TiC}$ particles. Results showed that high energy input refined and homogenized dispersion of TiC reinforcement, thus achieving enhanced wear and tensile properties. However, if the input energy was too high, the columnar dendrites of the NMCs would be coarsened and the wear and tensile properties would be decreased.

Based on the SLM and LMD laser additive manufacturing processes, the $\mathrm{WC}, \mathrm{TiC}$ and other micron ceramic particle reinforced nickel matrix (Inconel 718, Inconel 625 , etc.) composite systems are investigated [73, 74], and through the adjustment of laser process parameters and composite components, the ceramic reinforced particles and the composite material components were adjusted ( $\mathrm{Ti}, \mathrm{M}) \mathrm{C}(\mathrm{M}$ is $\mathrm{Nb}, \mathrm{Mo})$ gradient interface layer constructed between $\gamma$ matrix, which effectively controls and eliminates the forming defects such as residual stress, interface micropores and microcracks. The generation mechanism of the interfacial graded layer was shown in Figure 13 . The gradient interface can effectively improve the wetting behavior of the ceramic/matrix interface, balance the hardness difference between the two, and play a role in transferring load, adjusting the deformation behavior of the reinforced particles and the matrix.

$\mathrm{TiC}$ particles were injected into Inconel 690 alloy to fabricate NMCs with laser direct deposition [75]. It was observed that the composite microstructure changed

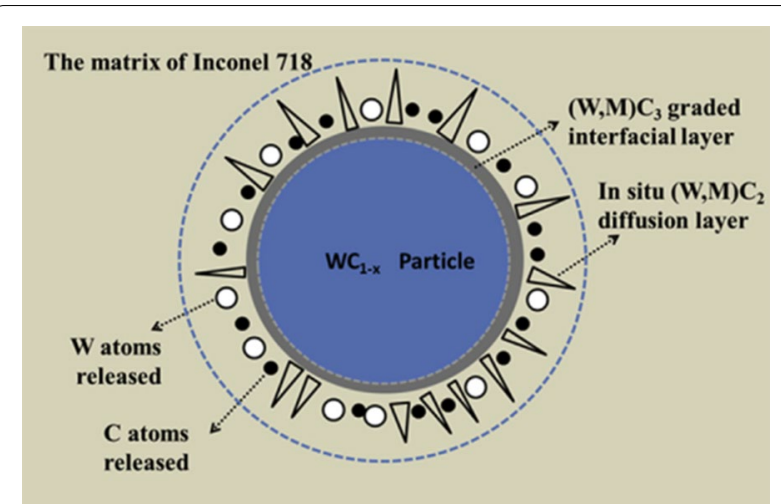

Figure 13 Schematic diagram of the generation mechanism of the interfacial graded layer [73]

with the increased amount of $\mathrm{TiC}$ particles content (Figure 14). The grain size became smaller as the $\mathrm{TiC}$ increased and the grain shape transformed from columnar to equiaxed. When the $\mathrm{TiC}$ content reached to 30 vol.\%, dispersed distributed dendritic $\mathrm{TiC}$ phases appeared in the microstructure with a fine size. Furthermore, 40 vol. $\% \mathrm{TiC}$ content could lead to a $42 \%$ improvement on the wear resistance of the composites.

As a rapid solidification process, laser AM generated high temperature gradient and high thermal stress within fabricated parts and bring about defects of cracks, warpage, and even delamination. The use of Invar, which had low coefficient of thermal expansion (CTE), was reported to be an effective solution to such an issue. Li et al. fabricated $\mathrm{TiC}$ reinforced Invar $(64 \mathrm{wt} . \% \mathrm{Fe}+36 \mathrm{wt} . \% \mathrm{Ni}$ ) matrix composites (IMCs) using laser AM process [76]. Experimental results showed that $\mathrm{TiC}$ reinforced IMCs had low CTE, high hardness, and high yield strength.

Man et al. [77] in-situ cladded a TiN reinforced MMC layer on a NiTi substrate by laser AM in a nitrogen atmosphere. The wear resistance of NiTi substrate was increased by a factor of two. Van Acker et al. [78] laser cladded $\mathrm{WC} / \mathrm{W}_{2} \mathrm{C}$ reinforced NMCs composites on steel substrates using laser AM and investigated effects of $\mathrm{WC} / \mathrm{W}_{2} \mathrm{C}$ content as well as carbide size on wear performance. It was proved that an increase in $\mathrm{WC} /$ $\mathrm{W}_{2} \mathrm{C}$ content and a decrease in carbide size favored the enhancement of wear resistance.

The preparation of ceramic reinforced nickel matrix composites is another important way to improve the mechanical properties of nickel base superalloys, which can make the composites exhibit higher specific strength, specific stiffness and heat resistance without reducing the toughness. Ma et al. [79] prepared $\mathrm{Ni} /$ $\mathrm{Al}_{2} \mathrm{O}_{3}$ nanocomposites. It was found that the addition of nanoparticles can significantly reduce the heat 

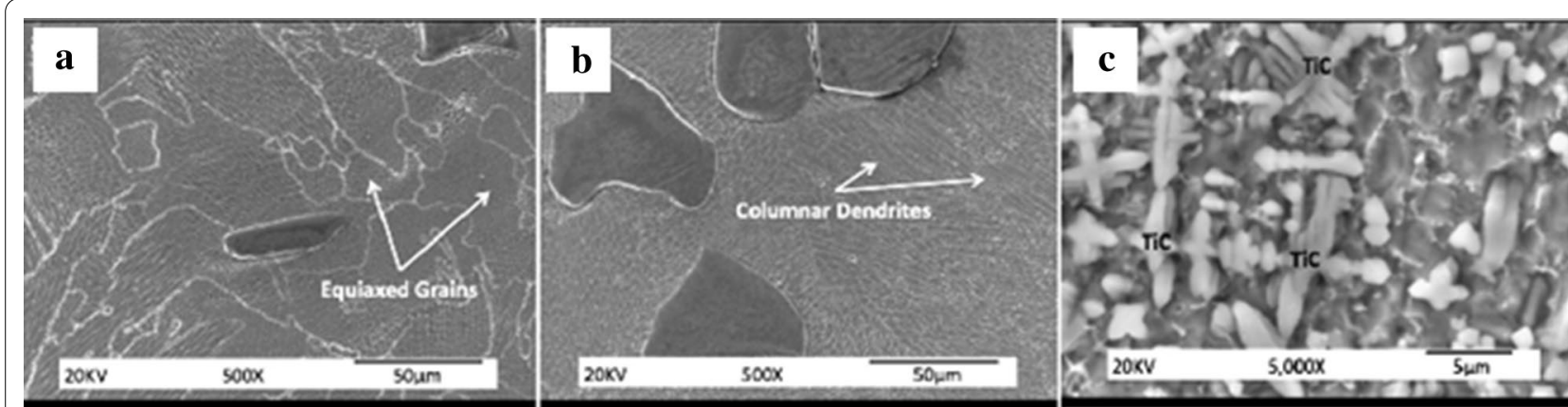

Figure 14 Microstructure of Inconel 690/TiC samples: a Equiaxed grains found in 8.7 vol.\% TiC, b Groups of columnar dendrites in 15.3 vol.\% TiC layer, c Dendritic TiC phase (43 vol.\% TiC) [75]

affected zone of the composite system and increase the melting zone. As shown in Figure 15, the special melting and solidification characteristics of $\mathrm{Ni}$ based nanocomposites under laser irradiation are revealed. This abnormal phenomenon is mainly due to the fact that nanoparticles can reduce the thermal conductivity of the system, thus reducing the heat transfer to the substrate. In the meantime, the nanoparticles can increase the viscosity of the melt, inhibit the thermal capillary flow, and then reduce the thermal convection in the molten pool.

Based on the design and control of gradient interface between reinforcement phase and matrix, a regulatory mechanism was proposed to realize the synergistic enhancement of strength and toughness of particle reinforced NMCs. It solved the contradiction between "strength" and "toughness" in the process of laser additive manufacturing composite components. This can also provide a useful way to improve the interface bonding properties and the formability of components. Ho et al. [80] found that in the $\mathrm{WC}-\mathrm{W}_{2} \mathrm{C} /$ Inconel 718 composite fabricated by laser $\mathrm{AM}$, the grains were easy to nucleate on the surface of $\mathrm{WC}-\mathrm{W}_{2} \mathrm{C}$ and formed a diffusion layer at the interface. The microstructure evolution was due to the small wetting angle between the reinforcement phase and the matrix.

Additionally, Gu [74] found that the laser additive manufacturing of nano $\mathrm{TiC}$ ceramic particles reinforced NMCs could reduce the probability of columnar crystal and crack formation. The matrix structure was cellular crystal and the reinforcement phase was evenly distributed. This was due to the fact that the nano reinforced particles were easy to become non-uniform nucleation points of the matrix melt, so as to improve the nucleation rate of the matrix, to promote the formation of cellular crystals and to refine the structure. Based on the idea of nano ceramic composite and nano modification, through the understanding and regulation of metallurgical thermodynamics and dynamic behavior in the process of non-equilibrium rapid melting and solidification of laser $\mathrm{AM}$, the spatial distribution of nano particles, crystal growth structure and morphology could be controlled and arranged, and the strength and toughness of NMCs fabricated by laser AM could also be improved. In addition, it should be pointed out that the multi-function of laser AMed composite components was also an important research direction in AM field. The surface roughness of the nickel-based nanocomposites was controlled

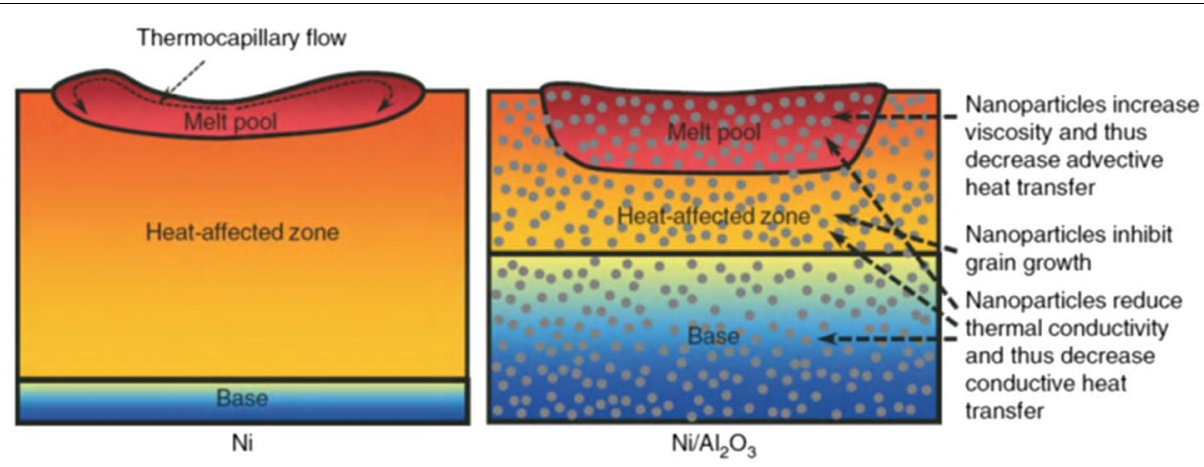

Figure 15 Mechanisms for metallurgical modification by nanoparticles during laser melting of Ni-based composites [79] 
by adjusting the laser process parameters. As shown in Figure16, The superhydrophobic surface was obtained [81].

\subsection{Cobalt Matrix Composites}

Cobalt matrix composites (CMCs) were manufactured by Weng et al. by LMD with pre-laced powders of Co42 alloy, $\mathrm{B}_{4} \mathrm{C}, \mathrm{SiC}$ and $\mathrm{Y}_{2} \mathrm{O}_{3}$ on the Ti6Al4V substrate [82]. The reinforcement phases in the CMCs were in-situ reaction products such as $\mathrm{CoTi}, \mathrm{CoTi}_{2}, \mathrm{NiTi}, \mathrm{TiC}, \mathrm{TiB}_{2}, \mathrm{TiB}$, $\mathrm{Cr}_{7} \mathrm{C}_{3}$, and $\mathrm{Ti}_{5} \mathrm{Si}_{3}$. It was reported that the wear resistance of the composite was improved over 10 times more than the substrate, due to the high microhardness up to 1134 $\mathrm{HV}_{0.2}$ of the composites. Further research indicated that the content of $\mathrm{SiC}$ in the powders was a key influence factor of the quality of the composites. Coarse microstructure and increased brittleness would appear while the $\mathrm{SiC}$ content reached $14 \mathrm{wt} . \%$.

Similarly, the Co42 and $\mathrm{SiC}$ mixture could synthesize $\mathrm{Ti}_{5} \mathrm{Si}_{3} / \mathrm{TiC}$ reinforced CMCs on the Ti-6Al-4V substrate by LMD [83]. In this case, a 3 times more enhanced microhardness was obtained compared to the substrate. But the SiC addition should be lower than 20 wt.\%, otherwise cracks would occur in the CMCs.

Moreover, Co42+ TiN mixed powders were also used to fabricate CMCs on the Ti-6Al-4V substrate by LMD [84]. There were $\gamma-\mathrm{Co} / \mathrm{Ni}, \mathrm{CoTi}, \mathrm{CoTi}_{2}, \mathrm{Co}_{3} \mathrm{Ti}, \mathrm{NiTi}, \mathrm{TiN}$, $\mathrm{CrB}, \mathrm{Cr}_{7} \mathrm{C}_{3}$, $\mathrm{TiC}, \mathrm{TiB}$, and $\mathrm{TiC}_{0.3} \mathrm{~N}_{0.7}$ phases in the CMCs. It was deduced that the TiN particles dissolved and precipitated during the laser process. On the surface of undissolved TiN particles, TiC was in-situ formed in the molten pool. As the TiN addition increased to $30 \mathrm{wt} . \%$, the ternary compound $\mathrm{TiC}_{0.3} \mathrm{~N}_{0.7}$ was generated from the reaction between $\mathrm{TiC}$ and $\mathrm{TiN}$ [84].

To improve the surface wear resistance of Cobalt base alloy Stellite $6(29 \% \mathrm{Cr}, 4.5 \% \mathrm{~W}, 1.5 \% \mathrm{Mo}, 1.2 \% \mathrm{C}$, Co balance, wt.\%), the powder mixture consisted of $70 \%$ Stellite 3 and 30\% Stellite 21 was used to fabricate CMCs by
LMD. The microstructure was observed with the results of fcc Co solid solution, $\mathrm{M}_{7} \mathrm{C}_{3}$ carbide, (W, Co) ${ }_{6} \mathrm{C}$ and (Co, Mo ${ }_{3} \mathrm{C}$ carbides, indicating a hypereutectic microstructure with the carbides as the primary phase and the total volume fraction of carbides was about $40 \%$. The laser AMed CMCs was found served precisely to the application of sealing structure. Industrial test results showed that no leakage was discovered on the sealing surface under specified duration of 30000 cycles [85].

Furthermore, the effect of aging heat treatment on the microstructure and related wear resistance of laser AMed CMCs was studied by Ding et al. The reinforcement in the composites was $\mathrm{VN}$ particles and the aging temperature ranged from $550{ }^{\circ} \mathrm{C}$ to $750{ }^{\circ} \mathrm{C}$ [86]. The results revealed that the aging treatment of $550{ }^{\circ} \mathrm{C}$ and $650{ }^{\circ} \mathrm{C}$ did not influenced the phases in the CMCs, which consisted of $\gamma-\mathrm{Co}, \mathrm{Cr}_{23} \mathrm{C}_{6}, \mathrm{Co}_{5.47} \mathrm{~N}, \sigma-\mathrm{FeV}$ and $\mathrm{VN}$ phase. However, the $750{ }^{\circ} \mathrm{C}$ aging treatment would lead to the disappearance of $\sigma-\mathrm{FeV}$ phase. The precipitate phases, such as $\mathrm{Cr}_{23} \mathrm{C}_{6}$ and $\mathrm{VN}$ would gradually increased as aging treatment temperature increased, which improve the microhardness and wear resistance [86].

In-situ reaction was also applied to regulate and control the microstructure and related properties of laser AMed CMCs. The raw materials for the reactions was mixed powders composed of $5.0 \mathrm{wt} . \% \mathrm{VN}$ powders, Ti powders (1.2 wt.\%-9.6 wt.\%) and balance of Co-based powders. The reaction products mainly consisted of $\gamma$-Co, $\mathrm{Cr}_{23} \mathrm{C}_{6}, \mathrm{Co}_{5.47} \mathrm{~N}, \sigma-\mathrm{FeV}$ and $\mathrm{VN}$ phases, and new TiN and $\mathrm{VC}$ phases as the reaction products from the equation: $\mathrm{TiC}+\mathrm{VN}=\mathrm{TiN}+\mathrm{VC}$, were detected in the composite coatings after adding Ti [87]. It was found that the addition of Ti effectively decreased the length of the dendrites and formed fine equiaxed grains. The action mechanism of $\mathrm{Ti}$ on the microstructure of VN/Co-based composite was shown in Figure 17.

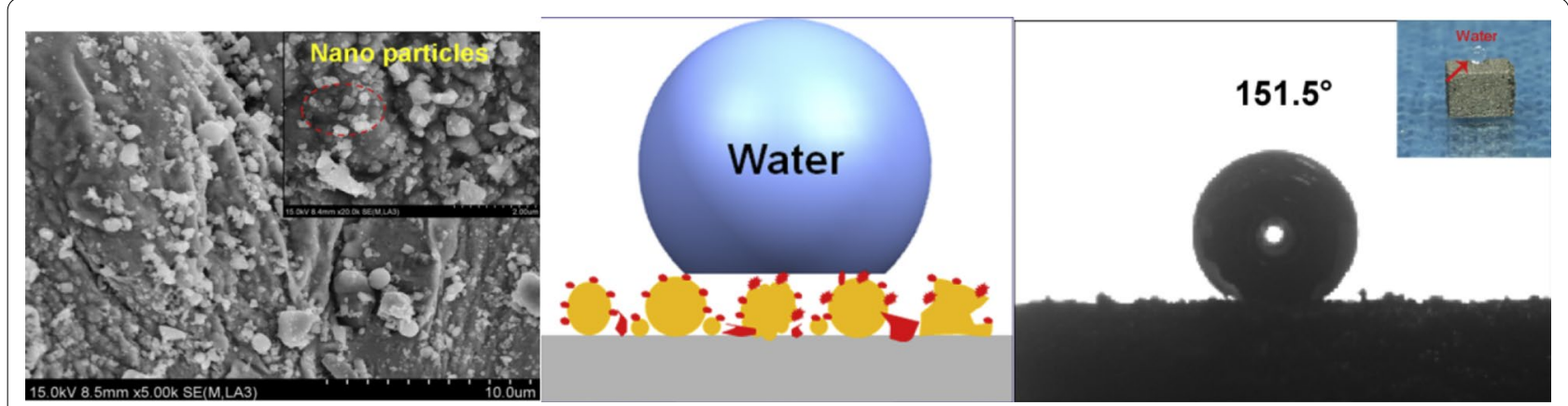

Figure 16 The superhydrophobic surface of laser AM NMCs[81]. a Morphology of the surface; b Schematic diagram of the wetting model; $\mathbf{c}$ Contact angle images of TiC/Inconel 718 nanocomposites 


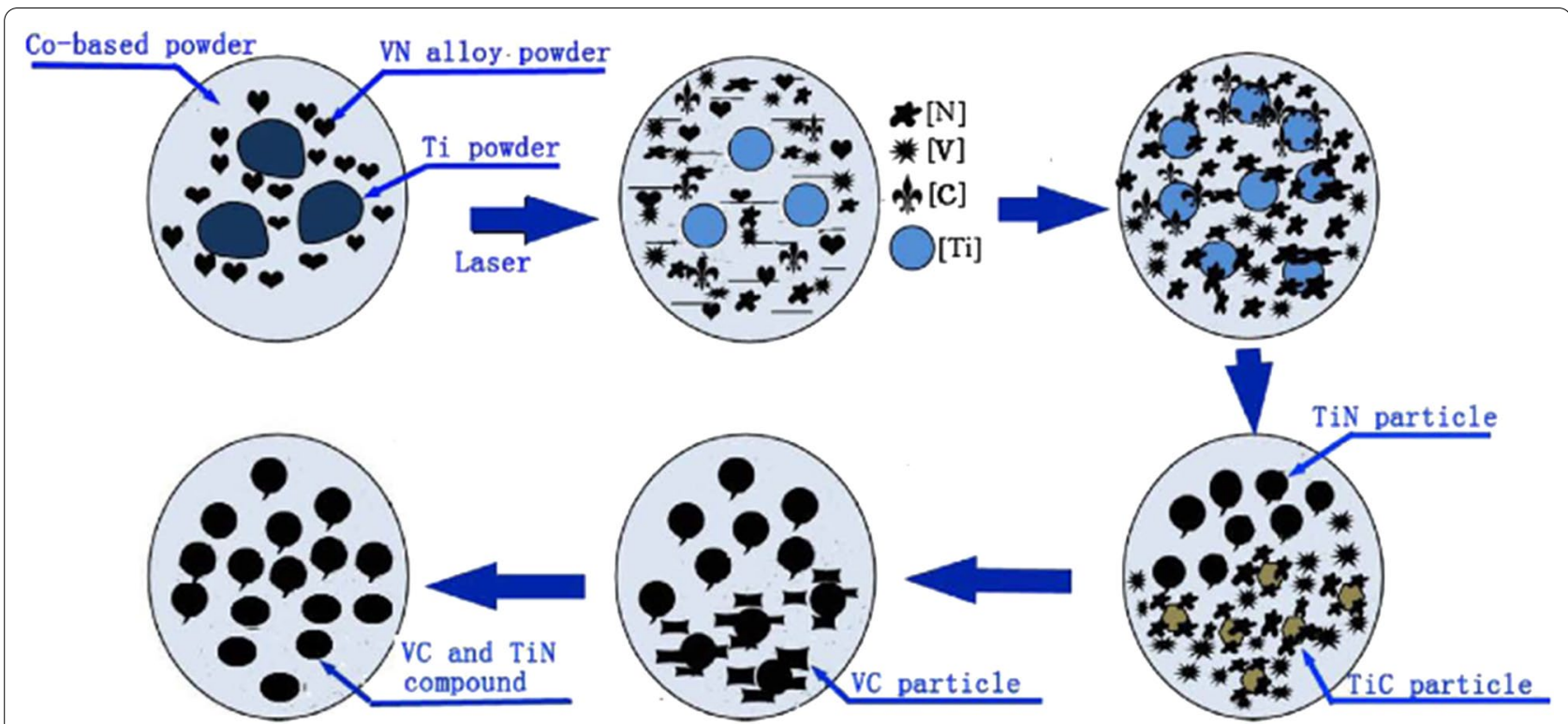

Figure 17 Diagram illustration for the action mechanism of Ti on the microstructure of VN alloy/Co-based composite coatings [87]

\section{Outlook}

\subsection{Formation Mechanism and Strengthening Principle of Reinforcement Phase in Laser AMed MMCs}

There are many disadvantages in traditional metal materials, such as low specific strength, specific stiffness and poor corrosion resistance. However, the design and preparation of "multiphase materials" like particle reinforced MMCs and in-situ synthesized MMCs manufactured by laser AM are effective ways to solve these problems [88, 89]. With the introduction of strengthening particles (such as ceramic particles, rare earth elements and in-situ formed compounds) into the metal matrix, the formation mechanism, distribution and interfacial bonding properties of strengthening phases restrict the performance of AMed components. Therefore, in-situ analysis techniques (such as high-speed synchrotron radiation $\mathrm{X}$-ray microscopy, small angle neutron scattering (SANS)) can be used to study the distribution of strengthening phase, the formation of metallurgical defects and the evolution of microstructure $[90,91]$. It would be very important for deeply understanding the formation mechanism and strengthening principle of reinforcement phase in laser AMed MMCs.

\subsection{Importance of the Material and Process Design of Laser AM MMCs}

The material system, preparation and processing of MMCs by laser AM are designed to achieve "adding the right material to the right place". In the past, the traditional process chain was to obtain the corresponding performance through structure design and processing technology on the basis of material selection. In this method, the realization of performance is passive, and the process of trial and optimization was inevitable. However, in the future, the development of laser AM technology can choose materials according to the expected performance. The generality of design and controllability of AM process would be emphasized on realizing the expected performance (such as high speed, high efficiency, high precision and high reliability) actively.

In addition, the precise design of multiphase materials can be customized through material design software and high-throughput experimental methods [92-94]. The influence of material composition on laser processing and AMed components properties could be quantitatively predicted. The purpose is to screen out multiphase materials with expected characteristics and properties in a short time, so as to improve the research and development efficiency of new MMCs for laser AM.

Moreover, the post heat treatment should also be considered as an important factor influencing the properties of AMed MMCs. Proper heat treatment parameters could significantly regulate and control the distribution of reinforcements and improve the mechanical properties $[95,96]$.

\subsection{Innovative Structure Design Based on the Special Properties of Laser AM MMCs}

Based on the innovative structure design of laser AM components, high performance and multi-function of components could be realized. With the development of laser AM technology, especially for the severe 
service environment requirements in aerospace field, the mechanical properties of AMed materials and components are no longer the only research goal, and the multi-functional materials is becoming an important development trend. With the help of the complex structure and multi material integration forming ability of additive manufacturing technology, and through the innovative structural design of bionic structure, topology optimization structure, metamaterial and super structure, it is expected to achieve breakthroughs in the functional fields such as light, sound, heat, electricity, magnetism and so on $[88,97]$. Innovative structural design, multi-functional design and precise process control are the important directions for realizing the integration of material structure function. The numerical simulation based on multi physical fields and the combination of machine learning and other emerging artificial intelligence technologies can provide theoretical guidance for the design and optimization [98-100].

\subsection{Key Role of Simulation, Monitoring and Optimization on the Laser AM Process}

At present, two key problems still need to be solved in laser AM MMCs. Firstly, the microstructure of the AMed MMCs are difficult to control under the condition of intense unstable heating cycle and high-speed cooling. Secondly, in the process of laser AM, the accumulation and coupling of thermal stress, microstructure stress, solidification shrinkage stress and other complex stresses can easily lead to deformation and even cracking of materials.

In order to solve these problems, the method of numerical simulation could be applied to establish theoretical models. The numerical simulation of laser additive manufacturing needs to consider various physical metallurgical behaviors of multiphase, including energy, momentum and mass transmissions in the non-equilibrium molten pool under high-energy laser irradiation. Most of current numerical simulation models could only calculate the process of several laser AM layers. They need to be further expanded to a full-scale component level during the whole AM process and the control of thermal field, flow field, phase field and stress field should be all covered. Furthermore, the simulation accuracy and computational efficiency of the physical model should be matched reasonably. On the other hand, it is necessary to study the influence of structural characteristics, AM process and AM environment on the quality and stability based on numerical simulation method [101-103]. With the simulation results, the prediction of AM quality, efficiency and potential risks could be realized.

In future, to broaden the application of AM technology in aerospace and other fields, it is essential to establish a digital simulation platform including material data, model data, process strategy database and specific integration of AM equipments, AM process monitoring. In addition, with the application of machine learning, new MMCs would be virtually designed and manufactured automatically under the digital platform.

\begin{abstract}
Acknowledgements
Not applicable.

Authors' Contributions

$\mathrm{HX}$ and NL conceived the idea of the study; NL wrote the manuscript; WL, YW, ZZ, TY and GZ provided the data. All authors read and approved the final manuscript.
\end{abstract}

\section{Authors' Information}

Neng Li, born in 1985, is currently a senior engineer at Beijing Institute of Aeronautical Materials, China. He received his PhD degree on Materials Science \& Engineering from Beijing Institute of Aeronautical Materials, China, in 2019. His main research interests include welding and additive manufacturing.

Wei Liu, born in 1984, is currently a senior engineer at Beijing Institute of Aeronautical Materials, China. He received his PhD degree on Materials Science \& Engineering from Beihang University, China, in 2015.

Yan Wang, born in 1992, is currently a PhD candidate at Beijing Institute of Aeronautical Materials, China.

Zijun Zhao, born in 1995, is currently an assistant engineer at Beijing Institute of Aeronautical Materials, China. He received his master degree on Materials Processing Engineering from Tianjing University, China, in 2019.

Taiqi Yan, born in 1993, is currently an engineer at Beijing Institute of Aeronautical Materials, China. He received his master degree on Materials Processing Engineering from Beihang University, China, in 2018.

Guohui Zhang, born in 1992, is currently an engineer at Beijing Institute of Aeronautical Materials, China. He received his master degree on Mechanical Manufacture and Automation from Dalian University of Technology, China, in 2018.

Huaping Xiong, born in 1969, is currently a professor and a PhD candidate supervisor at Beijing Institute of Aeronautical Materials, China. His main research interests include Brazing and additive manufacturing.

\section{Funding}

Supported by National Natural Science Foundation of China (Grant Nos. 51775525, 51605456) and Beijing Nova Program (Grant No. Z201100006820094) from Beijing Municipal Science \&Technology Commission.

\section{Competing Interests}

The authors declare no competing financial interests.

Received: 11 November 2020 Revised: 9 March 2021 Accepted: 11 March 2021

Published online: 12 April 2021

\section{References}

[1] TW Clyne, P J Withers. An introduction to metal matrix composites. Cambridge: Cambridge University Press, 1995.

[2] KS Al-Hamdani, JW Murray, T Hussain, et al. Controlling ceramic-reinforcement distribution in laser cladding of MMCs. Surface and Coatings Technology, 2020, 381: 125128.

[3] H M Wang, C M Wang, LX Cai. Wear and corrosion resistance of laser clad $\mathrm{Ni}_{2} \mathrm{Si} / \mathrm{NiSi}$ composite coatings. Surface and Coating Technology, 2003, 168(2): 202-208. 
[4] Y B Hu, W L Cong, X L Wang, et al. Laser deposition additive manufacturing of TiB-Ti composites with novel three-dimensional quasi continuous network microstructure: effects on strengthening and toughening. Composites Part B: Engineering, 2018, 133: 91-100.

[5] S Kundu, M Hussain, V Kumar, et al. Direct metal laser sintering of TiN reinforced Ti6Al4V alloy based metal matrix composite: Fabrication and characterization. The International Journal of Advanced Manufacturing Technology, 2018, 97: 2635-2646.

[6] M P Behera, T Dougherty, S Singamneni, Conventional and additive manufacturing with metal matrix composites: A perspective. Procedia Manufacturing, 2019, 30: 159-166.

[7] J Zhang, B Song, Q Wei, et al. A review of selective laser melting of aluminum alloys: Processing, microstructure, property and developing trends. Journal of Materials Science \& Technology, 2019, 35(2): 270-284.

[8] D B Miracle. Metal matrix composites-from science to technological significance. Composites Science and Technology, 2005, 65(15-16): 2526-2540.

[9] Y B Hu, W L Cong. A review on laser deposition-additive manufacturing of ceramics and ceramic reinforced metal matrix composites. Ceramics International, 2018, 44: 20599-20612.

[10] N Li, S Huang, G D Zhang, et al. Progress in additive manufacturing on new materials: A review. Journal of Materials Science \& Technology, 2019, 35(2): 242-269.

[11] ASTM, Standard Terminology for Additive Manufacturing Technologies (F-2792-12a), 2015.

[12] S H Huang, P Liu, A Mokasdar, et al. Additive manufacturing and its societal impact: a literature review. International Journal of Advanced Manufacturing Technology, 2013, 67: 1191-1203.

[13] F D Ning, W L Cong, Y B Hu, et al. Additive manufacturing of carbon fiber reinforced plastic composites using fused deposition modeling: effects of process parameters on tensile properties. Journal of Composite Materials, 2017, 51(4): 451-462.

[14] K K Chawla. An introduction to metal matrix composites. Materials Characterization, 1994, 33(1): 83.

[15] M A Xavior, J P A Kumar. Machinability of hybrid metal matrix composites: A review. Procedia Engineering, 2017, 174: 1110-1118.

[16] M Wang, D Chen, Z Chen, et al. Mechanical properties of in-situ TiB 2 / A356 composites. Materials Science and Engineering: A, 2014, 590: 246-254.

[17] Y Shen, $X \mathrm{Li}$, T Hong, et al. Effects of TiB 2 particles on microstructure and mechanical Properties of an in-situ TiB 2 -Al-Cu-Li matrix composite. Material Science and Engineering: A, 2016, 655: 265-268.

[18] J Geng, T Hong, Y Ma, et al. The solution treatment of in-situ sub-micro $\mathrm{TiB}_{2} / 2024$ Al composite. Materials \& Design, 2016, 98: 186-193.

[19] Y Zhou, SWen, CWang, et al. Effect of TiC content on the Al-15Si alloy processed by selective laser melting: Microstructure and mechanical properties. Optics \& Laser Technology, 2019, 120: 105719.

[20] A Mouritz. Introduction to aerospace materials. Sawston: Woodhead Publishing Limited, 2012: 394-400.

[21] T Q Yan, P J Tang, B Q Chen, et al. Effect of annealing temperature on microstructure and tensile properties of AISi10Mg alloy fabricated by selective laser melting. Journal of Mechanical Engineering, 2020, 56(8): 37-45. (in Chinese)

[22] JW Hunt. Aluminum metal matrix composites today. Materials Science Forum, 2000, 331: 71-84

[23] N Kang, Y Fu, P Coddet, et al. On the microstructure, hardness and wear behavior of Al-Fe-Cr quasicrystal reinforced Al matrix composites prepared by selective laser melting. Materials \& Design, 2017, 132: 105-111.

[24] YX Li, P F Zhang, P K Bai, et al. Microstructure and properties of Ti/ TiBCN coating on 7075 aluminum alloy by laser cladding. Surface and Coatings Technology, 2017, 334: 142-149.

[25] D D Gu, Y Yang, L X Xi, et al. Laser absorption behavior of randomly packed powder-bed during selective laser melting of $\mathrm{SiC}$ and $\mathrm{TiB}_{2}$ reinforced Al matrix composites. Optics \& Laser Technology, 2019, 119 : 105600.

[26] SCTjong, ZY Ma. Microstructural and mechanical characteristics of in-situ metal matrix composites. Materials Science and Engineering: $R$ : Reports, 2000, 29(3): 49-113.

[27] H Wang, G Li, Y Zhao, et al. In-situ fabrication and microstructure of $\mathrm{A}_{2} \mathrm{O}_{3}$ particles reinforced aluminum matrix composites. Materials Science \& Engineering: A, 2010, 527(12): 2881-2885.
[28] A Riquelme, E Rodriguez, M Dolores, et al. Role of laser cladding parameters in composite coating (Al-SiC) on aluminum alloy. Journal of Thermal Spray Technology, 2016, 25(6): 1177-1191.

[29] K J Lijay, J D R Selvam, I Dinaharan, et al. Microstructure and mechanical properties characterization of AA6061/TiC aluminum matrix composites synthesized by in-situ reaction of silicon carbide and potassium fluotitanate. Transactions of Nonferrous Metals Society of China, 2016, 26(7): 1791-1800.

[30] T Tarasova, G Gavozdeva, R Ableyeva. Aluminium matrix composites produced by laser based additive manufacturing. Materials Today: Proceedings, 2019, 11: 305-310.

[31] H J Rathod, T Nagaraju, K G Prashanth, et al. Tribological properties of selective laser melted Al-12Si alloy. Tribology International, 2019, 137 : 94-101.

[32] $\mathrm{G}$ Chen, $\mathrm{G} X$ Sun. Study on in-situ reaction-processed $\mathrm{Al}-\mathrm{Zn} / \mathrm{a}-\mathrm{Al}_{2} \mathrm{O}_{3}(\mathrm{P})$ composites. Materials Science and Engineering: A, 1998, 244(2): 291-295.

[33] TW Clyne, P J Withers. An introduction to metal matrix composites. New York, NY, USA, 1993.

[34] W Xu, S Xiao, L U Xin, et al. Fabrication of commercial pure Ti by selective laser melting using hydride-dehydride titanium powders treated by ball milling. Journal of Materials Science \& Technology, 2019, 35(2): 322-327.

[35] SCTjong. Recent progress in the development and properties of novel metal matrix nanocomposites reinforced with carbon nanotubes and graphene nanosheets. Materials Science and Engineering: R: Reports, 2013, 74(10): 281-350.

[36] D J Lloyd. Particle reinforced aluminium and magnesium matrix composites. Metallurgical Reviews, 1994, 39(1): 1-23.

[37] I Shishkovsky, N Kakovkina, V Sherbakov. Graded layered titanium composite structures with $\mathrm{TiB}_{2}$ inclusions fabricated by selective laser melting. Composite Structures, 2017, 169: 90-96.

[38] Y Diao, K Zhang. Microstructure and corrosion resistance of $\mathrm{TC}_{2} \mathrm{Ti}$ alloy by laser cladding with $\mathrm{Ti} / \mathrm{TiC} / \mathrm{TiB}_{2}$ powders. Applied Surface Science, 2015, 352: 163-168.

[39] C A Terrazas, L E Murr, D Bermudez, et al. Microstructure and mechanical properties of Ti-6Al-4V-5\% hydroxyapatite composite fabricated using electron beam powder bed fusion. Journal of Materials Science \& Technology, 2019, 35(2): 309-321.

[40] Q Fang, P S Sidky, M G Hocking, et al. Cracking behaviour of carbon coating on SiC fibre and residual stresses in Ti/SiC MMCs. Surface and Coatings Technology, 1998, 100(1-3): 264-270.

[41] M J Wang, H Huang, M Wen, et al. Effect of spark plasma sintering temperature on the consolidation of SiC fiber reinforced titanium alloy matrix composites. Materials Science Forum, 2017, 898: 957-963.

[42] X Luo, Y Q Wang, Y Q Yang, et al. Effect of C/Mo duplex coating on the interface and tensile strength of $\mathrm{SiC}_{\mathrm{f}} / \mathrm{Ti}-21 \mathrm{Al}-29 \mathrm{Nb}$ composites. Journal of Alloys and Compounds, 2017, 721: 653-660.

[43] P Mogilevsky, A Werner, H J Dudek. Application of diffusion barriers in composite materials. Materials Science and Engineering: A, 1998, 242(1): 235-247.

[44] L J Huang, U Geng, HY Xu, et al. In situ TiC particles reinforced Ti6Al4V matrix composite with a network reinforcement architecture. Materials Science \& Engineering: A, 2011, 528(6): 2859-2862.

[45] Y Zhang, J Sun, R Vilar. Characterization of (TiB+TiC)/TC4 in situ titanium matrix composites prepared by laser direct deposition. Journal of Materials Processing Technology, 2011, 211(4): 597-601.

[46] E O Akser, KL Choy. Finite element analysis of the stress distribution in a thermally and transversely loaded Ti-6Al-4V/SiC fiber composite. Composites Part A-Applied Science and Manufacturing, 2001, 32(2): 243-251.

[47] G P Li, D Li, Y Y Liu, et al. Microstructure of second-phase particles in Ti-5Al-4Sn-2Zr-1Mo-0.2Si-1 Nd alloy. Metallurgical and Materials Transactions A, 1997, 28: 1595-1605.

[48] X Zhang, F Song, Z Wei, et al. Microstructural and mechanical characterization of in-situ TiC/Ti titanium matrix composites fabricated by graphene/Ti sintering reaction. Materials Science and Engineering: $A$, 2017, 705: 153-159.

[49] A B Kloosterman, B J Kooi, J D Hosson. Electron microscopy of reaction layers between $\mathrm{SiC}$ and Ti-6Al-4V after laser embedding. Acta Materialia, 1998, 46(17): 6205-6217. 
[50] D Giuranno, N Sobczak, G Bruzda, et al. Studies of the joining-relevant interfacial properties in the $\mathrm{Si}-\mathrm{Ti} / \mathrm{C}$ and $\mathrm{Si}-\mathrm{Ti} / \mathrm{SiC}$ systems. Journal of Materials Engineering and Performance, 2020, 29: 4864-4871.

[51] LJ Huang, L Geng, H Peng. Microstructurally inhomogeneous composites: is a homogeneous reinforcement distribution optimal. Progress in Materials Science, 2015, 71: 93-168.

[52] D Ren, S Li, H Wang, et al. Fatigue behavior of Ti-6Al-4V cellular structures fabricated by additive manufacturing technique. Journal of Materials Science \& Technology, 2019, 35(2): 285-294.

[53] A Hooyar, E H Shima, K Damon, et al. Recent developments and opportunities in additive manufacturing of titanium-based matrix composites: A review. International Journal of Machine Tools and Manufacture, 2018, 133: 85-102.

[54] A Hooyar, E H Shima, K Damon, et al. Nanoindentation and wear properties of $\mathrm{Ti}$ and $\mathrm{Ti}-\mathrm{TiB}$ composite materials produced by selective laser melting. Materials Science and Engineering: A, 2017, 688: 20-26.

[55] C Cai, C Radoslaw, J Zhang, et al. In-situ preparation and formation of $\mathrm{TiB} / \mathrm{Ti}-6 \mathrm{Al}-4 \mathrm{~V}$ nanocomposite via laser additive manufacturing: Microstructure evolution and tribological behavior. Powder Technology, 2019, 342: 73-84.

[56] Y Feng, K Feng, C Yao, et al. Microstructure and properties of in-situ synthesized $\left(\mathrm{Ti}_{3} \mathrm{Al}+\mathrm{TiB}\right) / \mathrm{Ti}$ composites by laser cladding. Materials \& Design, 2018, 157: 258-272.

[57] M Xia, A Liu, Y Lin, et al. Densification behavior, microstructure evolution and fretting wear performance of in-situ hybrid strengthened Ti-based composite by laser powder-bed fusion. Vacuum, 2019, 160: 146-153.

[58] N Li, YXiong, H P Xiong, et al. Microstructure, formation mechanism and property characterization of $\mathrm{Ti}+\mathrm{SiC}$ laser cladded coatings on Ti6Al4V alloy. Materials Characterization, 2019, 148: 43-51.

[59] N Li, W Liu, H P Xiong, et al. In-situ reaction of Ti-Si-C composite powder and formation mechanism of laser deposited Ti6Al4V/(TiC $\left.+\mathrm{Ti}_{3} \mathrm{SiC}_{2}\right)$ system functionally graded material. Materials \& Design, 2019, 183: 108155

[60] TE Raghy, A Zavaliangos, M W Barsoum, et al. Damage mechanisms around hardness indentations in $\mathrm{Ti}_{3} \mathrm{SiC}_{2}$. Journal of the American Ceramic Society, 1997, 80(2): 513-516.

[61] Y C Zhou, Z M Sun, S Q Chen. In-situ hot pressing/solid-liquid reaction synthesis of dense titanium silicon carbide bulk ceramics. Materials Research Innovations, 1998, 2: 142-146.

[62] M W Barsoum, T E Raghy, Synthesis and characterization of a remarkable ceramic: $\mathrm{Ti}_{3} \mathrm{SiC}_{2}$. Journal of the American Ceramic Society, 1996, 79(7): 1953-1956.

[63] M Barsoum, T Zhen, S Kalidindi, et al. Fully reversible, dislocation-based compressive deformation of $\mathrm{Ti}_{3} \mathrm{SiC}_{2}$ to $1 \mathrm{GPa}$. Nature Materials, 2003, 2: 107-111.

[64] RY Qin, X J Zhang, S Q Guo, et al. Laser cladding of high Co-Ni secondary hardening steel on $18 \mathrm{Cr}$ 2Ni4WA steel. Surface and Coating Technology, 2016, 285: 242-248.

[65] D Gu, J Ma, H Chen, et al. Laser additive manufactured WC reinforced Fe-based composites with gradient reinforcement/matrix interface and enhanced performance. Composite Structures, 2018, 192: 387-396.

[66] B Song, Z Wang, Q Yan, et al. Integral method of preparation and fabrication of metal matrix composite: Selective laser melting of in-situ nano/submicro-sized carbides reinforced iron matrix composites. Materials Science and Engineering: A, 2017, 707: 478-487.

[67] N Kang, W Ma, L Heraud, et al. Selective laser melting of tungsten carbide reinforced maraging steel composite. Additive Manufacturing, 2018, 22: 104-110.

[68] H Chen, D Gu, L Deng, et al. Laser additive manufactured high-performance Fe-based composites with unique strengthening structure. 2020, Journal of Materials Science \& Technology, doi.org/https:// doi.org/10.1016/j.jmst.2020.04.011.

[69] S Gopagoni, JY Hwang, A R P Singh, et al. Microstructural evolution in laser deposited nickel-titanium-carbon in situ metal matrix composites. Journal of Alloys and Compounds, 2011, 509(4): 1255-1260.

[70] J Liang, Y Liu, J Li, et al. Epitaxial growth and oxidation behavior of an overlay coating on a Ni-base single-crystal superalloy by laser cladding. Journal of Materials Science \& Technology, 2019, 35(2): 344-350.
[71] C Hong, D D Gu, D H Dai, et al. Laser additive manufacturing of ultrafine TiC particle reinforced Inconel 625 based composite parts: tailored microstructures and enhanced performance. Materials Science \& Engineering: A, 2015, 635: 118-128.

[72] C Hong, D Gu, D Dai, et al. Laser metal deposition of TiC/Inconel 718 composites with tailored interfacial microstructures. Optics \& Laser Technology, 2013, 54: 98-109.

[73] TRong, D Gu. Formation of novel graded interface and its function on mechanical properties of $W_{1-x}$ reinforced Inconel 718 composites processed by selective laser melting. Journal of Alloys and Compounds, 2016, 680: 333-342.

[74] D Gu, S Cao, K Lin. Laser metal deposition additive manufacturing of TiC reinforced Inconel 625 composites: influence of the additive TiC particle and its starting size. Journal of Manufacturing Science \& Engineering 2017, 139(4): 041014.

[75] J M Wilson, Y C Shin. Microstructure and wear properties of laserdeposited functionally graded Inconel 690 reinforced with TiC. Surface and Coatings Technology, 2012, 207: 517-522.

[76] X C Li, J Stampfl, F B Prinz, Mechanical and thermal expansion behavior of laser deposited metal matrix composites of Invar and TiC. Materials Science and Engineering: A, 2000, 282(1): 86-90.

[77] H C Man, S Zhang, FT Cheng, et al. In situ formation of a TiN/Ti metal matrix composite gradient coating on NiTi by laser cladding and nitriding. Surface and Coatings Technology, 2006, 200(16): 4961-4966.

[78] K Van Acker, D Vanhoyweghen, R Persoons, et al. Influence of tungsten carbide particle size and distribution on the wear resistance of laser clad WC/Ni coatings. Wear, 2005, 258 (1-4): 194-202.

[79] C Ma, L Chen, C Cao, et al. Nanoparticle-induced unusual melting and solidification behaviours of metals. Nature Communications, 2017, 8: 14178.

[80] IT Ho, YT Chen, A C Yeh, et al. Microstructure evolution induced by inoculants during the selective laser melting of IN718. Additive Manufacturing, 2018, 21: 465-471.

[81] H Zhang, D Gu, C Ma, et al. Surface wettability and superhydrophobic characteristics of Ni-based nanocomposites fabricated by selective laser melting. Applied Surface Science, 2019, 476: 151-160.

[82] FWeng, HYu, C Chen, et al. Microstructures and wear properties of laser cladding Co-based composite coatings on Ti6Al4V. Materials \& Design 2015, (80): 174-181

[83] FWeng, HYu, J Liu, et al. Microstructure and wear property of the $\mathrm{Ti}_{5} \mathrm{Si}_{3} / \mathrm{TiC}$ reinforced Co-based coatings fabricated by laser cladding on Ti6AI4V. Optics \& Laser Technology, 2017, 92: 156-162.

[84] FWeng, H J Yu, C Z Chen, et al. Microstructure and property of composite coatings on titanium alloy deposited by laser cladding with Co42+TiN mixed powders. Journal of Alloys and Compounds, 2016, 686: 74-81.

[85] Y Ding, R Liu, J Yao, et al. Stellite alloy mixture hardfacing via laser cladding for control valve seat sealing surfaces. Surface and Coatings Technology, 2017, 329: 97-108.

[86] L Ding, S Hu, X Quan, et al. Effect of aging treatment on microstructure and properties of $\mathrm{VN}$ alloy reinforced Co-based composite coatings by laser cladding. Materials Characterization, 2017, 129: 80-87.

[87] L Ding, S Hu, X Quan, Effect of Ti on the microstructure evolution and wear behavior of VN alloy/Co-based composite coatings by laser cladding. Journal of Materials Processing Technology, 2018, 252: 711-719.

[88] W Liu, N Li, B Zhou, et al. Progress in additive manufacturing on complex structures and high-performance materials. Journal of Mechanical Engineering, 2019, 55 (20): 128-151,159. (in Chinese)

[89] G Muvvala, D P Karmakar, A K Nath. In-process detection of microstructural changes in laser cladding of in-situ Inconel 718/TiC metal matrix composite coating. Journal of Alloys and Compounds, 2018, 740: 545-558.

[90] ZY Ding, Q D Hu, W Q Lu, et al. In-situ study on hydrogen bubble evolution in the liquid $\mathrm{Al} /$ solid $\mathrm{Ni}$ interconnection by synchrotron radiation X-ray radiography. Journal of Materials Science \& Technology, 2019, 35(7): 1388-1392.

[91] M Ohnuma, K Hono, S Linderoth. Small-angle neutron scattering and differential scanning calorimetry studies on the copper clustering stage of Fe-Si-B-Nb-Cu nanocrystalline alloys. Acta Materialia, 2000, 48(20): 4783-4790. 
[92] X J Zhang, K Z Chen, X A Feng. Material selection using an improved Genetic Algorithm for material design of components made of a multiphase material. Materials \& Design, 2008, 29(5): 972-981.

[93] L Zhou, J Xiong, Z Guo, et al. Design and preparation of gradient graphite/cermets self-lubricating composites. Journal of Materials Science \& Technology, 2018, 34(8): 122-130

[94] B C Salzbrenner, J M Rodelas, J D Madison, et al. High-throughput stochastic tensile performance of additively manufactured stainless steel. Journal of Materials Processing Technology, 2017, 241: 1-12.

[95] G D Zhang, H P Xiong, H Yu, et al. Microstructure evolution and mechanical properties of wire-feed electron beam additive manufactured Ti-5Al-2Sn-2Zr-4Mo-4Cr alloy with different subtransus heat treatments. Materials \& Design, 2020: 109063.

[96] H M Wang, Y F Liu. Microstructure and wear resistance of laser clad $\mathrm{Ti}_{5} \mathrm{Si}_{3} / \mathrm{NiTi}_{2}$, intermetallic composite coating on titanium alloy. Materials Science and Engineering: A, 2002, 338: 126-132.

[97] H P Xiong, S Q Guo, W Liu, et al. Aeronautical metal material additive manufacturing technology. Aviation Industry Press, 2019. (in Chinese)
[98] H B Yin, J Han, J Liu, et al. The application design of machine learning in intelligent learning support system. Advanced Materials Research, 2011, 403-408: 1535-1538

[99] KTakahashi, Y Tanaka. Material synthesis and design from first principal calculations and machine learning. Computational Materials Science, 2016, 112: 364-367.

[100] A A Chehade, T M Belgasam, G Ayoub, et al. Accelerating the discovery of new DP steel using machine learning-based multiscale materials simulations. Metallurgical and Materials Transactions A, 2020: 1-12.

[101] A Panesar, M Abdi, D Hickman, et al. Strategies for functionally graded lattice structures derived using topology optimization for additive manufacturing. Additive Manufacturing, 2018, 19: 81-94.

[102] M Pham, C Liu, I Todd, et al. Damage-tolerant architected materials inspired by crystal microstructure. Nature, 2019, 565(7739): 305-311.

[103] J Song, Y Chew, G Bi, et al. Numerical and experimental study of laser aided additive manufacturing for melt-pool profile and grain orientation analysis. Materials \& Design, 2018, 137(5): 286-297.

\section{Submit your manuscript to a SpringerOpen ${ }^{\circ}$ journal and benefit from:}

- Convenient online submission

- Rigorous peer review

- Open access: articles freely available online

- High visibility within the field

- Retaining the copyright to your article

Submit your next manuscript at springeropen.com 